\title{
Business Cycle Synchronization in the Enlarged EU*
}

\author{
Zsolt Darvas and György Szapáry ${ }^{\S}$
}

October 2004

\begin{abstract}
This paper analyzes the synchronization of business cycles between new and old EU members using various measures. The main findings are that Hungary, Poland and Slovenia have achieved high degree of synchronization for GDP, industry and exports, but not for consumption and services. The other CEECs have achieved less or no synchronization. There has been significant increase in synchronization of GDP and its major components within euro zone. This lends support to the argument of OCA endogeneity but there is also evidence of a world cycle. The consumption-correlation puzzle remains, but its magnitude has greatly diminished in the euro zone members.
\end{abstract}

JEL Classification numbers: E32, F41

Keywords: business cycle synchronization, consumption-correlation puzzle, EMU, new EU members, OCA endogeneity

\footnotetext{
${ }^{*}$ Revised in October 2004 for the joint ECB-IMF workshop on "Gobal financial integration, stability and business cycles: exploring the links" in Frankfurt.We are thankful for comments and discussions of conference and workshop participants at the ASSA 2004 Annual Meetings (San Diego), Magyar Nemzeti Bank (Budapest), Euro Area Business Cycle Network Workshop (Vienna), European University Institute (Florence), Austrian Economic Association (Vienna), and Viessmann Conference (Lisbon). The views expressed are those of the authors and do not necessarily reflect the official view of the Magyar Nemzeti Bank.

\# Magyar Nemzeti Bank and Corvinus University Budapest. E-mail: darvaszs@mnb.hu. Address: Szabadság tér 8-9, Budapest 1054, Hungary. Phone: +36-1-428-2660, Fax: +36-1-428-2590.

$\S$ Magyar Nemzeti Bank. E-mail: szaparygy@mnb.hu
} 


\section{Introduction}

In the ten new EU members - eight of which are former socialist countries from Central and Eastern Europe (CEECs) - attention is increasingly focused on the next step of the European integration process: entry into the euro zone. The benefits and costs of a currency union have been extensively analyzed in the literature, prompted in part by the discussions leading up to the creation of EMU and, more recently, by the discussion about the future enlargement of the euro zone ${ }^{1}$. The theoretical foundations of currency unions have been developed in the literature on optimum currency areas (OCA) pioneered by Mundell (1961) to which McKinnon (1963), Kenen (1969), Tavlas (1993), Bayoumi and Eichengreen (1996) and many other authors have subsequently contributed $^{2}$. The OCA theory postulates that the benefits of a currency union depend on whether the countries contemplating to form a monetary union share certain common characteristics, called the OCA properties. Among these properties, the similarity of business cycles features prominently, because if cycles are synchronized, the cost of foregoing the possibility of using counter-cyclical monetary policy is minimized. Therefore, when considering the appropriate timing of entry into the euro zone, satisfying the Maastricht criteria of nominal convergence of inflation, long term interest rates, fiscal deficit, public debt and exchange rate stability within ERM II is only one set of factors to be taken into account. The question also has to be asked whether the business cycles are sufficiently synchronized so that the new members can comfortably give up monetary and exchange rate policy independence.

The purpose of this paper is twofold: (1) to assess the current degree of business cycle synchronization in CEECs vis-à-vis the euro zone cycle and to see how it

\footnotetext{
${ }^{1}$ See, in particular, Eichengreen (1992), Emerson et al. (1992), De Grauwe (2002) and HM Treasury (2003). Csajbók and Csermely (2002) analyses the costs and benefits of the introduction of the euro in Hungary.

${ }^{2}$ See Mongelli (2002) for a comprehensive review of the OCA literature.
} 
compares to the current and earlier levels of synchronization in the euro area countries; and (2) to analyze the evolution over time of the business cycle synchronization in the euro zone countries and to see, in particular, whether it has increased since 1993-97, the run-up period to the EMU. This latter question is relevant because it has been argued in the literature that participation in a currency union may itself lead to greater synchronization of business cycles. This is referred to in the literature as the endogeneity of the OCA properties. Using a panel of thirty years of data for twenty industrial countries, Frankel and Rose (1998) find a strong positive relationship between trade integration and business cycle correlation. Therefore, to the extent that participation in a currency union increases trade integration, membership in a currency union will lead to more highly correlated business cycles. Rose (2000) finds that currency unions increase trade substantially and hence concludes that a country is more likely to satisfy the criteria for entry into a currency union ex post than ex ante. Krugman’s (1993) “lessons from Massachusetts” and results of Kalemli-Ozcan et al. (2001) warn however that trade integration might lead to specialization and therefore increase the likelihood of asymmetric shocks.

Since Rose (2000), many others have investigated the impact of common currencies on trade, for instance, Persson (2001), Glick and Rose (2001) Rose and Wincoop (2001), Frankel and Rose (2002), Bun and Klaassen (2002), Kenen (2002), and Micco, Stein and Ordoñez (2003). All these studies demonstrate a positive effect of common currencies on trade, although the effect found is smaller then the initial findings of Rose (2000). ${ }^{3}$ Another argument supporting the endogeneity of the OCA criteria as it may apply to the EMU is that the common monetary policy, supported by the discipline of the Stability and Growth Pact, eliminates or at least diminishes the

\footnotetext{
${ }^{3}$ For an overview of the findings of empirical research on the topic see Rose (2002).
} 
asymmetricity of policy responses. If policies are the source of shocks, EMU membership reduces the risk of asymmetricity of shocks.

There is a growing literature on business cycle correlation between the CEECs and the EU. In a survey paper Fidrmuc and Korhonen (2004b) report 27 studies dealing with this issue. Our research contributes to the business cycle comovement literature in the following ways. First, we look at a large number of countries: eight CEECs, ten euro zone countries and a control group consisting of the three EMU-outs and five other countries to check for the endogeneity of the OCA properties in the EMU. For the CEECs, we look at the last ten years, while for most of the other countries the last twenty years. We also include Russia in our investigation to document the shifts in comovements vis-à-vis this previously important trading partner of the CEECs. Second, there are some papers analyzing a broader or narrower group of CEECs with respect to synchronization, but these papers analyze GDP or industrial production only. ${ }^{4}$ We also analyze the major expenditure and sectoral components of GDP. From the perspective of OCA and common monetary policy, it is relevant to know to what extent are synchronized those components of GDP which drive aggregate demand and therefore influence inflation. The analysis of the comovement of GDP components also sheds some further light on the so-called "consumption-correlation puzzle" which is one of the six major puzzles in international macroeconomics according to Obstfeld and Rogoff (2000). Third, in order to make our findings robust, we use various measures to assess synchronization.

Perhaps the most popular method in the synchronization literature of CEECs was the bivariate Blanchard-Quah (1989) type SVAR decomposition of supply and demand shocks based on output and inflation data. ${ }^{5}$ Once supply and demand shocks are

\footnotetext{
${ }^{4}$ The exceptions are Boone and Maurel (1998 and 1999) who also study the unemployment rate.

5 Thirteen out of the twenty-seven papers surveyed by Fidrmuc and Korhonen (2004b) adopted this technique. The first applicantion of this method to CEECs was made by Frenkel et al. (1999). Fidrmuc
} 
identified separately for individual CEECs and Germany or the euro area, synchronization is assessed by the correlation between the shocks at home and in Germany/the euro area. However, the use of SVARs is largely debated even for countries having much longer sample periods ${ }^{6}$. Imposing long-run identifying restriction for six to ten years of data available for the CEECs would not make much sense in the framework of the SVAR model. There is also an important problem with the inflation rates of CEECs used by the studies, as price developments were heavily affected in the 1990s by price and trade liberalization and administrative price adjustments which led to large changes in relative prices. Moreover, most of the inflation data series are not stationary in the sample period which raises a problem that is quite difficult to handle.

Due to these deficiencies of the SVAR technique, we use detrended time series as cyclical measures and adopt various checks. We use five measurements of synchronization, two filtering techniques and two measures of euro area activity. Most previous empirical research on CEECs has looked at only cycle correlation with respect to Germany as a measure of comovement. We also analyze leads/lags, volatility and persistence of the cycle and a measure of impulse-response. Smaller leads/lags, less volatility, similar persistence, and equal impulse-response make the common monetary policy more suited for a country participating in a currency union. We made all our calculations with the two most popular filtering techniques in the business cycle literature: the Hodrick-Prescott and the Band-Pass filters. Both techniques have deficiencies, but if both reveal a similar trend, the finding can be regarded as more robust. Finally, as we are more interested in synchronization vis-à-vis the euro area as a whole rather than just Germany, we look at the euro area activity against which we

and Korhonen (2004a) present updated estimates which indicate large changes in results compared to earlier versions estimated on somehow shorter samples.

${ }^{6}$ See, for instance, Faust and Leeper (1997) and Cooley and Dwyer (1998). 
measure the synchronization of individual countries. For this purpose, we use an aggregate from the ECB area-wide model database and a common factor calculated by us, because the former is more burdened with measurement errors in the pre-1999 period.

It is necessary to say at the outset what are the questions that this paper does not investigate empirically. It does not try to investigate the sources of shocks. Identifying the sources of shocks is important because monetary policy can not deal with all types of shocks similarly. However, if business cycles are synchronized, it means that most likely the countries are not subject to significant asymmetric shocks. Another question our paper does not investigate empirically is what are the channels of transmission of business cycles from one country to another. The empirical evidence discussed in the literature shows that openness, trade integration and similarity of economic structures have a strong effect on international comovements. Investigating the sources of shocks and the transmission mechanism of business cycles remain challenging areas of research that exceeds the scope of this paper.

The rest of the paper is organized as follows. Section 2 explains the methodologies and Section 3 describes the data used. Section 4 presents and discusses the findings. Section 5 summarizes the main findings and concludes.

\section{Methodology}

Due to the theoretical and practical deficiencies of the popular SVAR technique indicated in the introduction, we use detrended time series as cyclical measures which are standard in the synchronization literature — and calculate various synchronization measures based on them. In the following, we describe the methodological issues related to detrending, the measurement of the euro area economic activity, and the measurement of synchronization. 


\subsection{Detrending}

The first issue we face is detrending. There are various detrending methods adopted in the literature and empirical results might depend on the specific filter adopted, as it is demonstrated in Canova (1998). Canova compared the properties of the cyclical components of seasonally adjusted US data as revealed by various filters and concluded that, both quantitatively and qualitatively, properties of business cycles vary across detrending methods and that alternative detrending methods extract different types of information from the data.

This result posts a warning sign for empirical business cycle research. In order to make our results more robust, we use and compare the results of the two most widely adopted filters in the literature, namely the Hodrick-Prescott filter (HP) and the BandPass filter (BP). Among these two, the BP filter is preferable from a theoretical point of view, as argued for instance by Stock and Watson (1999), since it intends to eliminate both high frequency fluctuations (which might be due to measurement errors and noise) and low frequency fluctuations (which rather reflect the long term growth component) ${ }^{7}$. However, the BP filter also has weaknesses, since in finite samples only various approximations could be used. ${ }^{8}$ In particularly, since we have only ten years of data for the CEECs, the application of the BP filter, i.e., filtering out cycles with less than eight years periodicity, the standard upper band adopted in the literature, might be questionable. Therefore, analyzing the results based on the two filters increases the

\footnotetext{
${ }^{7}$ Several criticisms of the HP filter have been raised in the literature. Some of the criticisms simply originate from the arbitrary choice of the smoothness parameter. In addition, Cogley and Nason (1995) showed that for different stationary series, the HP filter is not a high-pass filter, but suppresses high and low frequency cycles and amplifies business cycle frequencies, therefore creating artificial business cycles. Similar criticism was voiced by Harvey and Jaeger (1993), who showed hat the HP filter creates spurious cycles in detrended random walks and I(2) processes, and that the danger of finding large sample cross-correlations between independent but spurious HP cycles is not negligible. Another important weakness of the HP filter is the treatment of sudden structural breaks, as the HP filter smooths out its effect to previous and subsequent periods. Moreover, the HP filter works as a symmetric two-sided filter in the middle of the sample, but becomes unstable at the end and at the beginning of the sample, although end-point instability is also a weakness of BP filter. For both filters, it is recommended that three years at both ends of the sample of the filtered series be disregarded.
} 
robustness of our results, even if both of them have deficiencies. The adoption of these two filters also allows better comparison of our results to previous empirical research reported in the literature. ${ }^{9}$

\subsection{Measuring the euro area economic activity}

We use two measures of euro area economic activity: (1) a euro area aggregate from the ECB area-wide model database and (2) a common factor calculated by us. For the areawide model of the ECB, euro area aggregates have been calculated for various series back until $1970^{10}$. However, these series must include various measurement errors, because quarterly national accounts are not available for all countries for earlier years, and because aggregation is affected by exchange rate fluctuations when there were separate currencies before 1999. Therefore, we also calculated a dynamic factor model for the detrended data of five core countries of the EMU in order to identify a common factor vis-à-vis which we can measure synchronization. The countries used for this calculation are France, Germany and Italy, as these countries are the three largest in the EMU. Austria and the Netherlands are also included as they had fixed exchange rates to the Deutsche mark for a long period of time and were highly integrated with the German economy. In principle, we could have calculated the common factor of all EMU members and use that as the measure of the euro area economic activity. However, individual quarterly time series of all countries are not available for the full sample period, so we had to select. The countries selected are those identified also by Artis and Zhang (1998) as the “core” EMU countries on the basis of several variables

\footnotetext{
${ }^{8}$ For the BP filter we adopt the approximation suggested by Christiano and Fitzgerald (2003), which is the latest among the three mostly commonly adopted approximations in the literature.

${ }^{9}$ As a preliminary check, we also used the seasonal differencing filter. The results, even for the GDP components, were qualitatively the same as the results obtained with the HP and BP filtered seasonally adjusted time series.

10 For a description and further reference for the euro area aggregate national accounts see http://www.ecb.int/stats/stats.htm and Fagan et al (2001). The aggregate that we use has constant country composition and handles the issue of German unification so that there is no level shift in the series.
} 
chosen to reflect OCA considerations, except that we include Italy and exclude Belgium.

Dynamic factor models have recently gained renewed interest in the business cycle literature $^{11}$. In these models, there are unobservable measures of economic activity. These unobserved measures are either common factor(s) (for all or some groups of the countries/series analyzed) or idiosyncratic factors. For example, analyzing a single indicator like GDP, the following model might describe the transmission of the euro area business cycles among $k$ countries:

$$
\begin{aligned}
& y_{i, t}=\beta_{i}^{E U} z_{t}^{E U}+\beta_{i} z_{i, t}+u_{i, t} \quad i=1, \ldots, k \\
& z_{t}^{E U}=\gamma^{E U} z_{t-1}^{E U}+u_{t}^{E U} \\
& z_{i, t}=\gamma_{i} z_{i, t-1}+u_{i, t} \quad i=1, \ldots, k
\end{aligned}
$$

where $y_{i, t}$ is the detrended ${ }^{12}$ GDP of country $i, z_{t}^{E U}$ is the (unobservable) index of European activity, i.e. the common factor, and $z_{i, t}$ is the (unobservable) index of country specific economic activity not explained by the common factor. Hence, this formulation allows the adoption of the standard assumption behind empirical statespace models of no contemporaneous or lagged correlation among the error terms of the equations. The $\beta$-s and $\gamma$-s are parameters to be estimated along with the standard errors of the innovations. Note that there are $k+1$ state equations and $k$ observation equations leading to a large number of estimated parameters even in the case of independent errors.

Before estimation, we standardized the cyclical components of individual countries, which is a standard procedure in the literature. The reason for that is to have equal variances across countries in order to have the possibility of an equal role in the common factor. As smaller countries tend to have more volatile cycles than large

\footnotetext{
${ }^{11}$ See, for example, Gregory et al. (1997), Stock and Watson (1998), Forni and Reichlin (1998), Gregory and Head (1999), Forni et al. (2000), Kose et al. (2003), Monfort et al. (2003), Helbling and Bayoumi (2003) and Giannone et al. (2003).
} 
countries $^{13}$, small countries would receive higher weights without the transformation. Standardization ensures that all series are treated symmetrically, which does not imply that the common factor will explain equal portions of the variance of the standardized individual series. Since the common factor is estimated from standardized series, it will be no point to talk about the variance of the common factor, so that when we turn to the volatility of the cycles, only the results for the euro area aggregate will be analyzed.

There are various ways to estimate dynamic factor models. We chose the maximum likelihood (ML) estimation and Kalman-filtering of the state-space representation. Our choice stems from the small number of cross section units (five) which makes it virtually impossible to adopt other methods (e.g., the dynamic principal component analysis) requiring large cross sections. Our small cross-section leads to a reasonably small number of parameters to be estimated, hence the computation difficulties indicated by, for instance, Gregory et al. (1997) does not arise in our case. Indeed, our estimation converged to a unique maximum for various starting values.

\subsection{Measures of synchronization}

We use five measures to assess synchronization. Since we are interested in the analysis of temporal change in the synchronization of business cycles, we calculated our measures for various sub-periods. Note, however, that detrending and calculation of the common factor was performed for the longest available sample of each series.

(a) Correlation. Contemporaneous unconditional correlation between the business cycle of the euro area and that of individual countries in different time periods. We use nonoverlapping five-year long periods to study the changing pattern of correlations. We

\footnotetext{
${ }^{12}$ We calculate the common factor for both HP and BP filtered series.

${ }^{13}$ See, for instance, Gerlach (1988) and Head (1995).
} 
also calculated five-year rolling sample correlations, which led to similar results. We have therefore chosen the simpler way for expositional reasons.

(b) Leads or lags. We calculated the lead/lag for which the unconditional correlation is the largest. The interpretation of the results for this measure is the following: a value of zero indicates that contemporaneous correlation is the highest, negative values indicate that the euro area leads the country studied, while a positive number indicates the reverse. We have checked the values for up to 3 in order not to decrease the degrees of freedom too much, so the value of 3 indicates that the lead/lag is 3 or larger. From the perspective of optimum currency area, zero or small lead/lag would be optimal.

(c) Volatility of the cycles. We defined volatility as the squared deviation from the mean of the cycle, i.e., from zero. In order to evaluate the results more easily, we have normalized the values relative to the euro area.

(d) Persistence. The dynamic effect of any shocks depends on the persistence of the series: for highly persistent series, the shock has a long-lasting effect, while for weakly persistent series the effect of the shock diminishes sooner. Consequently, from the perspective of synchronization, similar persistence is rather important. The measure we use is the first order autocorrelation coefficient of the cycle. Persistence defined this way reflects a mixture of the effects of various shocks and the effects of transmission mechanism through which these shocks pass on to the economies. Some shocks could have longer-term effects while others might diminish sooner, and some economies could react to a given shock differently than the other. Therefore, this simple measure does not allow the identification of the relative importance of various shocks and the way the economies react to them; rather this measure reflects the aggregate effect of the 
similarities of shocks and their transmission. We do not formulate any normative statement on whether a "high" or a "low"' persistence is better, we are simply interested in whether persistence is similar across countries. As it is documented in the literature, the estimation of autocorrelation coefficients is downward biased in the case of large outliers and it is also documented that for noisy series the autocorrelation coefficient tends to be smaller. Therefore, our measure also gives an indication of the possible presence of outliers and noise in the series which, again, should be small when there are no country specific shocks.

(e) Impulse-response. The accumulated effect (up to six quarters) of a euro area shock (proxied as a shock to the common factor) on the individual countries. When correlation is contemporaneous and large and the volatility and the persistence of the cycle is the same as in the euro area, then this measure will not deliver results different from the previous ones. However, whenever any of the above conditions are not satisfied, then it can give an additional indicator of synchronization by showing a measure of the magnitude of the impact of a euro area shock. Moreover, by calculating the impact from a VAR, which by definition includes own lags as well, this indicator can assess whether the results from the previous unconditional correlation coefficient are blurred by persistence. To some extent, this can be regarded as a summary measure of the previous four measures of synchronization. The six-quarter period for adding up the responses was selected to measure the cumulative impact for a period which is usually regarded as the one during which monetary policy takes its effect.

The impulse-responses were calculated from three-variable VARs including the common factor, the euro area aggregate, and the individual country studied. We calculated our measure based on the "generalized impulse-response function" of Pesaran and Shin (1998), which is independent of the ordering of the variables. The lag 
lengths of the VARs were selected with Sims's likelihood-ratio test for each country, with six lags being the largest possible value. We calculated the accumulated impulseresponse up to six quarters and normalized it with the effect of the common factor on the euro area itself. Therefore, the value of one indicates perfect synchronization according to this measure. Due to the large number of parameters to be estimated, we estimated the models for the most recent ten-year long period of 1993-2002, hence we cannot study the temporal change in the impact. ${ }^{14}$ We look at the impulse-response only for GDP, not its components.

\section{Data}

We include in our study the eight CEECs (Estonia, Czech Republic, Hungary, Latvia, Lithuania, Poland, Slovak Republic, Slovenia), ten members of the EMU (Austria, Belgium, France, Finland, Germany, Ireland, Italy, Netherlands, Spain, Portugal) ${ }^{15}$, and various other countries as a control group. The latter includes the EMU-outs (Denmark, Sweden and the United Kingdom), the other European countries (Switzerland and Norway), the United States and Japan to represent the other two main economic areas, and also Russia to represent the country which was formerly the most important trading partner of CEECs. The role of the control group is to assess whether there is evidence of the endogeneity of the OCA properties in the EMU and whether there is evidence of a "world business cycle”.

Our analysis covers GDP and its major expenditure and sectoral components: private consumption, investments, exports, imports, industrial production, and services. We do not include government consumption as it is a policy-driven aggregate, the

\footnotetext{
${ }^{14}$ Note that quarterly GDP data of Ireland is available only since 1997, so its sample period is shorter than in the case of all other countries. Due to the shorter sample, we have set the largest possible order of the VAR to three.

${ }^{15}$ Greece and Luxembourg are not included in the OECD's Quarterly National Accounts database which is our main source of statistics. The only Greek time series available at a quarterly frequency is gross industrial production, which we will compare to value added of industry available for other countries.
} 
analysis of which falls outside of the scope of this paper. Furthermore, we do not study agricultural production and construction which have a small share in GDP and are subject to country specific shocks, such as seasonal factors (agriculture) or policies (for instance, housing subsidies or the availability of mortgage loans).

Our sample includes quarterly data between 1983-2002 grouped in four nonoverlapping five-year periods: 1983-87; 1988-92; 1993-97 and 1998-2002. ${ }^{16}$ Most of our data are from the OECD’s Quarterly National Accounts database. The other sources and a full description of data availability is detailed in the Data Appendix. Unfortunately, not all time series are available for the full period. Most notably, CEECs' times series start only in $1993^{17}$, but data for expenditure and sectoral components of GDP are not available for all CEECs, and some of the available data starts later than 1993. For the euro area aggregate, the sectoral breakdown of GDP is available only since 1991, hence industrial production and services are studied only for the period since 1991.

\section{Results}

Since we examine a relatively large number of countries (26) and use two measures of euro area economic activity, two filters and five measures of synchronization, and since we look at several measures of economic activity (GDP and its components) during consecutive five-year long periods, it would be cumbersome to show all the results. Therefore, we first analyze the comovement in GDP cycles in detail, classify the countries into some groups and continue with a less detailed description of the results for the rest of the aggregates, underlying the similarities and differences with the

\footnotetext{
${ }^{16}$ Whenever data was available, detrending was performed for the 1980-2002 period in order to alleviate the instability property of both filters at the beginning of the sample period.

${ }^{17}$ Although for a few CEECs GDP is available for some years before 1993, we did not include them in the analysis in order to exclude most part of the transitional recession of the early nineties. In contrast to the US and most European data series, national accounts data series in CEECs are not seasonally adjusted. Therefore, we seasonally adjusted the times series using the Census X11 method.
} 
findings for GDP. Moreover, we present only the point estimate of various statistics but not their confidence bands for three reasons. First, for the large number of statistics we calculate, reporting their confidence bands would overburden the presentation and interpretation of results. Second, as we use filtered series which are themselves burdened with measurement errors, the confidence bands, calculated by standard ways, could reflect only the uncertainty related to estimation, but not the uncertainty inherent in the filtered series.

\subsection{Gross Domestic Product}

GDP is the most inclusive measure of economic activity and is therefore a useful proxy for overall business cycle, even though technically business cycles are defined as comovements of many aggregates. A large amount of empirical work in the business cycle and synchronization literature have used the GDP data, hence, GDP is the natural candidate to start with.

(a) Cycle correlation. Figures 1/a-b look at the evolution over time of correlation: Figure 1/a shows the contemporaneous correlation coefficients between the cycle of the euro area aggregate and the individual countries' cycles, while Figure 1/b shows the correlations using the common factor. The left column of panels shows the correlations based on the HP filter and the right column those based on the BP filter. The three rows of panels show results for the CEECs, the EMU members and the control group countries.

Among the CEECs, Hungary, Poland and Slovenia show strong improvement in cyclical correlation from the 1993-97 period to the 1998-2002 period the values of their correlation coefficients are comparable to that of several current EMU member states. However, the other five CEECs show almost no tendency to move toward greater 
synchronization during this period. It is useful to look at the shifts in correlations of the CEECs vis-à-vis Russia, formerly their most important trading partner. Figure 2 crossplots the correlation with both the euro area and Russia in 1993-97 and in 1998-02. In 1993-97, the three Baltic states correlated quite strongly with Russia, with coefficients ranging between 0.4-0.7, but the other CEECs did not exhibit any correlation in this period. By 1998-2002, correlation of the Baltic states with Russia declined substantially, while the correlation of the other CEECs increased, though it remained weak, except for the Czech Republic.

The strong correlation between the business cycles of the Baltic States and Russia in the earlier period is not surprising given that these states were part of the Soviet Union. Following the independence of the Baltic countries, their integration into the Russian economy came loose and their trade shifted increasingly toward Western countries. The lack of correlation of the other CEECs with Russia in the period 1993-97 is a result of both the collapse of trade with the Soviet Union and the rapid restructuring of trade of the CEECs toward the EU. The correlation of the Czech Republic seems to be a coincidence induced by the effects of independent currency crises — in the Czech Republic in 1997 and in Russia in 1998 - which led to a decline in GDP in both countries. It is noteworthy that the business cycle of Russia itself became more correlated with the EMU cycle between the two periods under consideration, an indication that Russia also is increasingly integrated into the world economy.

The EMU member countries have become more synchronized over time according to all the correlation measures calculated. The movement toward greater synchronization is particularly evident since 1993, the start of the run-up to the European Monetary Union. Interestingly, some of the control group countries are more synchronized than the smaller EMU-members (Portugal, Finland, Ireland). The most notable example is Switzerland, which shows as high a correlation as the most 
synchronized EMU members. The UK and Sweden also reveal stronger synchronization than the above mentioned three EMU-members.

These observations allow us to group the countries according to their degree of synchronization. We can split the CEECs into three groups: Hungary, Poland and Slovenia (labeled as CEE1 in the Tables 1-4), which are the most synchronized; the Czech Republic and Slovakia (CEE2), which were somehow synchronized in 1993-97 but not in 1998-2002; and the Baltic States (CEE3), which are not synchronized at all. We split the EMU countries into two groups: the "core” countries (Austria, Belgium, France, Germany, Italy and the Netherlands) which show higher synchronization, and the "peripheric" countries (Finland, Ireland, Portugal, Spain) which exhibit lower comovement. We also grouped together the three EMU-outs (Denmark, Sweden, the UK) and Switzerland, and show separately the US, Japan, and Russia in Tables 1-4. Table 1 presents a summary of correlations of GDP and all components for 1993-98 and 1998-2002.

(b) Leads and lags in the cycles. Table 2 shows the values of the leads/lags in the business cycles for the highest correlation value between the euro area and the individual countries examined. ${ }^{18}$ We have averaged the absolute value of the leads/lags in order, since averaging the raw data could cancel out positive and negative values. The three leading CEECs perform the best in this respect as well, having zero or close to zero phase shift in the most recent period. The other CEECs show a diverse picture with greater leads/lags. The tendency of almost all Western European countries to move toward contemporaneous correlation is further evidence of a strong business cycle synchronization in Europe. It is noteworthy that the US led the European cycle in the past 15 years while Japan lagged the European cycle in the past decade. 
(c) Volatility of the business cycles. Table 3 shows the country group average of volatilities of the individual countries' business cycles vis-à-vis the EMU aggregate business cycle. Two main observations can be made from an examination of the data. First, as reported also by Gerlach (1988) and Head (1995), smaller countries exhibit larger fluctuations. Gerlach speculates that possible explanations for this phenomenon are that larger countries may be more diversified, and small, more open economies may be subject to more foreign disturbances. The latter argument is not supported by the examples of Austria, Denmark and Switzerland which show even smaller volatilities than the large countries. Since these countries pursued stability oriented economic policies which were reflected in the stability of their currencies and inflation rates, it is more likely that economic policy plays an important role in cyclical volatility. Second, there has been a clear trend toward a reduction in volatility in all countries. For the EMU members and the control group countries, this decline is most evident if one looks at the whole period of twenty years examined from 1983-87 to 1998-2002. The decline in volatility is also evident for most of the CEECs over the last ten years. Hungary and Slovenia show the smallest volatility of cycles among CEECs, with amplitudes lower then in many current euro zone members. Poland and the Czech Republic also exhibit relatively low volatility.

The long-term decline in output volatility has been demonstrated for the US by Blanchard and Simon (2001). According to their findings, this decline can be traced to a decrease in the volatility of consumption and investment. Factors mentioned by the authors which may have contributed to this development are improvements in financial markets allowing better risk sharing and improvement in the conduct of monetary policy which led to a reduction in inflation volatility. These factors have probably also

\footnotetext{
${ }^{18}$ As said earlier, we have checked the values up to 3 , so the value of 3 indicates that the lead or lag is 3
} 
played a role in the decline of the European countries' relative volatility vis-à-vis the euro area cycle. It is interesting to note that in the leading CEECs, the volatility is about the same as in the EMU countries in the period 1998-2002. This would indicate that the role of country specific shocks has greatly diminished in these countries (see below).

(d) Persistence of the business cycle. Table 4 shows the evolution over time of the first order autocorrelation coefficient. From the 1993-97 to the 1998-2002 period, persistence in the cycles of CEECs tended to increase, which is indication of diminishing role of country specific shocks. There is only one country, Slovenia, whose value is substantially smaller than that of other CEECs, which is surprising based on our previous results on correlation, leads/lags, and volatility, and likely the consequence of single outlier observation.

In the case of EMU members, our results clearly illustrates a movement toward similar persistence, as in the 1980s and early 1990s the autocorrelation coefficients were rather scattered, but have become higher and dense by the final period. This again illustrates the increased synchronization in the EMU. Ireland, whose quarterly data is available only for the final period, is the only exception, but this is not surprising since the Irish cycle turned to be highly noisy.

(e) Impulse-response. Figure 3 shows the relative impact of a euro area shock on the individual countries, based on estimations for the 1993-2002 period. A value of one indicates a full transmittal of euro area shock to the cycle of the country, while a larger (smaller) value indicates greater (lesser) sensitivity; a value of zero means no transmittal at all. Among CEECs, Slovenia and Poland are the most sensitive to euro area shocks followed by Hungary, but even these three leading CEECs show lesser sensitivity to or larger. 
euro area shocks than most current EMU members. Taking into account the high contemporaneous correlation and the similarity in volatility of the above three CEECs with the cycle of the euro area, this result is likely due to the lower persistence of their cycles which is probably a reflection of differences in economic structures. The other five CEECs show zero sensitivity or even a counter cyclical pattern, which would indicate that their economic structures are even more divergent. Among EMU countries, Ireland stands out as the most sensitive country, since a shock has twice as big an effect than the effect of a shock on most of the other EMU countries. This result is likely the consequence of the extraordinary high growth rate of the Irish economy in the period considered, which could have led to higher cyclical volatility and sensitivity to foreign shocks.

(f) Methodological differences. In the above paragraphs, we highlighted the main findings, without discussing the differences resulting from the use of the two filtering techniques and the two different measures of euro area economic activity. The most important observation one can make is that the differences are not large enough to change the results or give reason to modify the interpretations. Nevertheless, it is worth mentioning them. As for the two filtering techniques, HP tends to reveal stronger synchronization and higher persistence than BP for the EMU members and the control group. This is not surprising based on the results of Cogley and Nason (1995) who, as mentioned earlier, showed that the HP filter tends to amplify the business cycle frequencies. For the CEEC countries, on the other hand, the two filters give similar results, which is probably due to the shorter time period examined for these countries. Comparing the results based on the euro area aggregate and the common factor, it is interesting to note that correlation coefficients tend to be less dispersed in the case of the common factor even in the case of the EMU-members that were not used to 
calculate the common factor. This is also true in the case non-EMU European countries, and indicates that the group of countries which includes the three largest EMU countries (Germany, France, Italy) captures well the euro area "common cycle”.

\subsection{Industry and Trade}

(a) Industrial Production. We continue the analysis with the second most frequently analyzed series of the synchronization literature: industrial production. Table 1 indicates that all three CEEC groups made some progress toward synchronization. The highest level, again, is achieved in our first group including Hungary, Poland, and Slovenia. Previous studies (for instance, Fidrmuc 2001b, Korhonen 2003 and Fidrmuc 2004) also tended to conclude that Hungary and Slovenia are well integrated, but among recent papers, only Boreiko (2002) and Artis et al (2004) found high correlation for Poland. It is interesting to note that the Czech Republic and Estonia also made some progress in synchronization, in contrast to the results observed for GDP. Among EMU countries, the peripheral group converged mainly due to Portugal, which was a clear outlier in 1993-98 but reached the the already high level of synchronization of the other euro zone countries by 1993-97. These results confirm the findings of Kaufmann (2003), who showed with a Bayesian cluster analysis of industrial production growth rates that EMU members belong to the same cluster and that the UK and Switzerland follow more closely the European rather than the overseas cycles.

The evolution of the leads/lags of the cycles shows increased contemporaneous comovement both for the three leading CEECs and all EMU members. Our persistence measure indicates similar or even larger values than most EMU members for the three leading CEECs and the Czech Republic, which could indicate that the role of country specific shocks were even less then in the EMU countries. 
The high level of synchronization of industrial production in the EMU members and also in several CEECs is not surprising, since industry generates a large proportion of foreign trade, which is one of the main channels through which synchronization can occur. In order to examine this question empirically, we continue with the analysis of exports and imports.

(b) Trade. The evolution of the correlation coefficients and the leads/lags of export cycles indicate a strong improvement in synchronization in all country groups (Tables 1-2), which is an indication of the globalized world of trade. The level of correlation is also very high in almost all countries and even exceeds the values observed for industrial production. Among the CEECs, in addition to the three leading countries, the Czech Republic and Slovakia also indicate high levels of correlation, in contrast to the case of GDP and industrial production. The only two countries standing out of the general trend are Norway and especially Russia, which could be explained by the specific commodity structure (oil) of their exports. As for relative volatilities, the CEECs tend to be more volatile especially the Baltics, which is likely the reflection of the fact that these countries are small and open, Russian trade cycles is also highly volatile which we attribute to its crisis and trade structure. Import cycles exhibit very similar trends, although the levels of correlation are somewhat lower. The lower level of import comovement across countries could be explained by the fact that imports are more sensitive to country specific shocks, such as government spending and changes in consumption behavior (see below).

\subsection{Consumption, services and investment}

We now turn to the analysis of the more domestically oriented expenditure components of GDP and start with private consumption. We only look at private consumption, since government consumption can be regarded as a policy-driven component, the 
synchronization of which, if any, is driven by policy actions. While in the EMU adherence to the Maastricht criteria and the Stability and Growth Pact may be a factor pushing toward greater fiscal policy synchronization, this is not the case in the CEECs for the time being.

There is a branch of business cycle literature that looks at the correlation across countries of consumption in comparison to output. The prediction of various one-good, complete-markets models is that consumption should be correlated across countries even if output does not correlate. The reason is that international risk sharing allows the separation of consumption from country specific income shocks. This result shows up both in simple two period optimizing models even when the coefficients of risk aversion and the subjective discount factors differ across countries (see, for example Chapter 5 of Obstfeld and Rogoff 1996), and in calibrated international real business cycle models (see, for example, Backus, Kehoe and Kydland, 1992). However, empirical studies have found that consumption is generally less synchronized across countries then GDP, which is regarded as one of the six major puzzles in international macroeconomics by Obstfeld and Rogoff (2000) and is referred to as the "consumption-correlation puzzle”. For instance, in a comprehensive paper Ambler et al (2004) extend the country coverage of previous papers by studying twenty industrial countries and consider all pairwise cross-country correlations, for the sample of 1960Q1-2000Q4, which is also broken into two subperiods at 1973. They conclude that the low cross-country correlation of consumption is the most important discrepancy with theory. ${ }^{19}$ Factors most of the time mentioned in the literature contributing to this "puzzle" are non-traded goods, imperfection of financial market integration that hinders risk pooling and consumption

\footnotetext{
${ }^{19}$ For further models and empirical research on this topic see also Cole and Obstfeld (1991), Devereux, Gregory, and Smith (1992), Backus, Kehoe and Kydland (1993), Baxter (1995), Bayoumi and MacDonald (1995), Stockman and Tesar (1995), Lewis (1996), Christodoulakis, Dimelis and Kollintzas (1995) and Corsetti, Dedola and Leduc (2003).
} 
smoothing, the presence of durable goods in consumption, imperfect competition, and trade costs.

Our data confirm that consumption is generally less synchronized than GDP. What is interesting from our perspective is that the comovement of private consumption has increased in all the euro zone countries since 1993-97 and in several of the control group countries as well, except in Denmark, Japan and Russia. Moreover, in most of the countries the increase in consumption correlation is larger than the increase in output correlation, as it is shown by Figure 4. The persistence of consumption cycles has also became more similar in the EMU (except Ireland) and in most of the control countries as well. This would indicate that the influence of the above mentioned factors that are behind the smaller comovement of private consumption across countries has been greatly diminished within the euro zone and, interestingly, also between the euro zone and the US. More globalized financial markets with fewer information barriers, less trade frictions and fewer asymmetric shocks are likely to be behind this development. Regarding international risk sharing, Table 5 shows that the stock of foreign assets and liabilities (FDI and portfolio investments in bonds and shares) rose indeed very sharply in the industrial world in the last ten years, a phenomenon observed in both EMU and non-EMU countries. ${ }^{20}$ This suggests the international consumption-correlation puzzle could further lessen in the future.

The picture is very different when we look at the CEECs. Only Poland shows some increase toward greater comovement, while the other countries have a negative correlation with the EMU aggregate, and the movement has been toward greater asynchronicity. ${ }^{21}$ The volatility of cycle relative to the euro area is also generally larger than in the case of output. We can only speculate about the reasons of this development.

\footnotetext{
${ }^{20}$ Hence, our results confirm the findings of Ahmadi (2004), who examines the decline in equity home bias over recent years. He attributes some of the decline to mutual fund investment and the internet.
} 
Trade and capital flows have been liberalized during the period under review which would argue in favor of greater, not smaller comovement. However, capital movement liberalization has been more gradual than trade liberalization in a number of CEECs. Furthermore, information barriers and stronger home bias in the financial markets due to the fact that capital markets had been restricted for many decades before the reforms have certainly contributed to weak risk pooling and less consumption smoothing. As Table 5 shows, the stock of assets invested abroad by the CEECs is negligible in sharp contrast with the development observed in the other countries examined.

Moreover, part of the causes for the lack of comovement in consumption can probably be traced back to the asymmetric shocks these countries were exposed in the early 1990s to and the way in which private consumption reacted to them. As known, all CEECs experienced a sharp contraction in incomes in the early part of the 1990s as a result of the collapse of trade with the former Soviet Union and the market oriented reforms (price and trade liberalization, reduction in subsidies, increase in inflation). This led to sharp reductions in consumption. When things turned for the better after the mind-1990s as the reforms gained hold and the new investments matured into production, the pent-up consumption demand, fueled sometimes by loose fiscal policy and high wage increases, led to a strong growth in consumption. These developments, which did not occur at the same time in all CEECs, surely contributed to the observed lack of comovement in private consumption vis-à-vis the EMU cycle. The move toward synchronization in Poland could be explained by the fact that GDP growth recovered faster in Poland then in the other CEECs which led to an earlier return to more normal patterns of private consumption. That the CEECs were subject to grater shocks is also reflected in the much higher volatility and larger leads/lags of private consumption compared to the euro area and the control group countries.

21 This phenomenon also characterises Russia, as its GDP cycles are positively correlated, while 
The above considerations make us believe that the lack of comovement in private consumption is a temporary phenomenon which will turn around as agents become better informed about and more familiarized with the possibilities of risk pooling and, more importantly, as the effects of reform-induced shocks will fade away and consumption patterns will assume a smoother long-term pattern. It will be interesting to redo our calculations a few years from now to test this assumption.

Since services account for a large part of consumption, not surprisingly they exhibit similar trends as private consumption: increase in synchronization in the euro zone and the control group countries and decrease in the CEECs, except in Poland and Slovakia. Volatilities and leads/lags are also larger and persistence is lower in the CEECs then in the euro area and the control group countries.

The cyclical correlation of investment is not very different from that observed for consumption. In the euro zone, one can observe a trend toward greater comovement since 1993-97, although the level of synchronization is generally lower than for GDP or its other expenditure components. It is interesting to point out the increased comovement of the US and Japan with the EMU cycle. This again lends support to the argument that the business cycle of major countries is becoming more globalized and that there is a world business cycle. As for the CEECs, only Poland and Hungary show some moves toward greater synchronization. Not surprisingly, the volatility of investment in the CEECs is higher then in the other countries, as investments have been very much influenced by the pace of the reforms, in particular privatization and the associated FDI inflows.

\section{Conclusion}

This paper examines the business cycle synchronization in the new EU members of

Central and Eastern Europe and the euro zone countries, together with a control group 
countries. We analyze GDP and its major expenditure and sectoral components. From the perspective of common monetary policy, it is relevant to know to what extent are synchronized those components of GDP which drive aggregate demand and therefor influence inflation. To make our findings more robust, we use five measures of synchronization, two filtering techniques and two measures of euro area economic activity against which we measure the comovements of individual countries' business cycles. One of our goals was to assess the current degree of synchronization of the CEECs and to see to what extent they are satisfying one of the OCA criteria, namely, the synchronization of their business cycles with the euro area. Our second goal was to see whether synchronization in the euro zone countries has increased in the run-up period to the EMU and since the start of the monetary union in order to test for OCA endogeneity. If there is evidence of such endogeneity, than CEECs can expect that once they are members of the EMU, their business cycles will start moving toward greater synchronization and they will need to be less concerned with initial idiosyncrasies. The empirical evidence suggests a number of conclusions of which we would like to emphasize the following.

We reverse the order followed so far and start with the EMU countries, which we can split into two groups: the "core” countries (Austria, Belgium, France, Germany, Italy and the Netherlands) which show higher synchronization, and the "peripheric" countries (Finland, Ireland, Portugal, Spain) which exhibit lower comovement. It is remarkable that the core EMU countries show a high degree of synchronization according to all the measures we use (high correlation, low volatility, small leads/lags, similar and high persistence, similar impulse-response) and this not only for GDP, but for its components as well. The synchronization has significantly increased between 1993-97 and 1998-2002, a period consisting of the run-up to EMU, followed by membership in the monetary union. For the peripheric EMU countries, the same overall 
trends can be observed, but their level of synchronization is less advanced, particularly for consumption and services. It is noteworthy that five out of the six core countries are the original funding members of the EU and the sixth, Austria, has had a fix exchange rate to the Deutsche mark since the mid-1970s. The peripheric countries had lower income per capita and were on a catch-up growth path toward the average of EU level, which could be a reason for the slower convergence in business cycles, since the catchup period could be accompanied by more intensive country specific shocks and uncertainties. Another reason could be that these countries joined the EU much later, hence they integrated into the EU trade later. Mitchell and Mouratidis (2003) also document an increase in the business cycle correlation in the euro zone, but they only analyze industrial production. Our study supports more broadly this trend and is thus more convincing.

Are the above trends evidence of the endogeneity of OCA? At first glance one could argue that yes, because synchronization has increased in all EMU members since the start of the run-up to EMU, when countries begun a process of meeting the Maastricht criteria of nominal convergence to be ready to adopt the euro in 1999. The reason why one can not be unambiguous about this interpretation is that the non-EMU European countries and even the US and to some extent Japan and Russia have also shown greater comovement with the euro cycle. This points toward the emergence of a "world business cycle” noted also by several authors, such as, for example, Gerlach (1988), Lumsdaine and Prasad (1997) and Kose et al. (2003).

Nevertheless, there are also some good news for the advocates of OCA endogeneity. First, the extent of synchronization is very high within the EMU core countries and the peripheric EMU countries have been moving toward that level. Second, synchronization has become high even for the traditionally less synchronized components of GDP, namely private consumption and services. Consumption, however, 
remains less synchronized than GDP. Our findings thus confirm the consumptioncorrelation puzzle, but they also show that this phenomenon is becoming significantly less important. Greater financial integration, more competition, reduced trade costs, including the elimination of separate currencies, and converging policies on the way to and within EMU have surely played a role in the greater business cycle synchronization. However, business cycle correlation is an evolutionary process and as Rogoff's (2001) Nail Soup story reminds us, we can not attribute all of the causes to one single ingredient, the euro. That said, it can be argued that the strong business cycle correlations observed in the EMU countries make the common monetary policy more suited and less of a problem for the current participants of the monetary union.

Turning to the CEECs, we can split them into three distinct groups: Hungary, Poland and Slovenia, which are the most synchronized; the Czech Republic and Slovakia, which are less synchronized; and the Baltic States, which are not synchronized at all.

It is quite remarkable that in the three leading countries in the first group, synchronization for GDP, industrial production and exports has improved dramatically to reach by 1998-2002 levels that are similar to that in the core EMU countries and even higher than in the EMU peripheric countries. Within a short period of time, these three CEECs were able to completely restructure their production and orient their exports away from the Eastern Block and toward the EU, leading to strong correlation with the euro area business cycle. Privatization and FDI inflows have played a crucial role in that process. The lesser synchronization of the Czech Republic and Slovakia is most likely due to the insufficient reforms and macroeconomic imbalances in the first half of the 1990s, leading to currency crises in the Czech Republic and Slovakia in 1997 and 1998, respectively, followed by a recession. Since the reforms have been accelerated and 
growth has resumed, these two countries will most probably reach as high a level of synchronization as the leading CEECs in the coming years.

The lack of synchronization in the Baltic countries is probably a reflection of the shocks that they experienced in the wake of the Russian crisis of 1998 . The economic and trade links of the Baltic countries with Russia at the time were much more extensive than was the case for the other CEECs. This is reflected in the significant positive correlation with the Russian business cycle in 1993-97, which however declined to close to zero or even to negative value by 1998-2002. Another factor could be the smaller share of intraindustry trade between the EU and the Baltic States, see, e.g. Fidrmuc (2001a and 2004). ${ }^{22}$ Finally, the Baltic countries' trade links with the Nordic countries are important and, as we have seen, the synchronization of the Nordic countries with the euro zone is not as strong.

In all the CEECs there is minimal or even negative correlation with the EMU cycle of private consumption and hence also of services. Consumption represents an important share in aggregate demand and the question can be asked whether it is wise for a country to give up monetary policy independence if there is no correlation in consumption, even though there is high correlation for GDP, driven by industrial production and export correlation. However, we have argued in the paper that the lack of consumption correlation was due to sudden shifts in consumption behavior and weak risk pooling, owing to greater information barrier and home bias in the financial assets markets. The influences of these factors are diminishing and the lack of private consumption correlation is likely to be a temporary phenomenon.

\footnotetext{
22 However, Frankel (2004) doubts the usefulness of distinguishing between intraindustry and interindustry trade from the perspective of synchronization. He notes that trade in inputs and intermediate products, constituting as it does a large share of today's trade, gives rise to positive correlations and yet it may be recorded as interindustry trade.
} 


\section{References}

Ahmadi, A., 2004. Equity home bias: A disappearing phenomenon?. University of California, Davis. Mimeo.

Ambler, S., Cardia E., ZimmermannC., 2004. International business cycles: what are the facts?. Journal of Monetary Economics 51 (2), 257-276.

Artis, M., Zhang W., 1998. Core and periphery in EMU: A cluster analysis. EUI Working Paper RSC 98 (37).

Artis, M., Proietti T., Marcellino M., 2004. Characterising the business cycle of accession countries, paper presented at the conference on "Economic, Econometric and Cross-Disciplinary Aspects of European Union Enlargement”, EUI, Firenze, May 13-15, 2004.

Backus, D.K., Kehoe P.J., Kydland F.E., 1992. International real business cycles. Journal of Political Economy, 745-775.

Backus, D.K., Kehoe P.J., Kydland F.E., 1993. International business cycles: theory vs. evidence. Federal Reserve Bank of Minneapolis, Quarterly Review, Fall 1993.

Baxter, M., 1995. International trade and business cycles. NBER Working Paper Series 5025.

Bayoumi, T., Eichengreen B., 1996. Operationalising the theory of optimum currency areas. CEPR Discussion Paper No. 1484.

Bayoumi, T., MacDonald R., 1995. Consumption, income, and international capital market integration. IMF Staff Papers 42, 552-76.

Blanchard, O., Simon J., 2001. The long and large decline in U.S. Output volatility. MIT, Department of Economics Working Paper 01-29.

Blanchard, O., Quah D., 1989. The dynamic effects of aggregate demand and supply Disturbances. The American Economic Review, 655-673.

Boone, L., Maurel M., 1998. Economic convergence of the CEECs with the EU. CEPR Discussion Paper 2018, Centre for Economic Policy Research, London.

Boone, L., Maurel M., 1999. An optimal currency area perspective of the EU enlargement to the CEECs. CEPR Discussion Paper 2119, Centre for Economic Policy Research, London.

Boreiko, D., 2002. EMU and accession countries: Fuzzy cluster analysis of membership. Oesterreichische Nationalbank Working Paper No 71.

Bun, M.J.G., Klaassen F.J.G.M., 2002. Has the euro increased trade? Tinbergen Institute Discussion Paper No. 02-108/02.

Canova, F. 1998. Detrending and business cycle facts. Journal of Monetary Economics 41., 475-512.

Christiano, L.J., Fitzgerald T.J., 2003. The band pass filter. International Economic Review 44 (2), 435-65.

Christodoulakis, N., Dimelis S.P., Kollintzas T., 1995. Comparisons of business cycles in the EC: Idiosynchracies and regularities. Economia 62, 1-27.

Cogley, T., Nason J.M., 1995. Effects of the Hodrick-Prescott filter on trend and difference stationary time series: Implications for business cycle research. Journal of Economic Dynamics and Control 19, 253-278. 
Cole, H.L., Obstfeld M., 1991. Commodity trade and international risk sharing: How much do financial markets matter? Journal of Monetary Economics 28, 3-24.

Cooley, T.F., Dwyer M., 1998. Business cycle analysis without much theory: A look at structural VARs. Journal of Econometrics 83 (1-2), 57-88.

Corsetti, G., Dedola L., Leduc S., 2003. International risk-sharing and the transmission of productivity shocks. Paper presented at the AEA 2003 meetings, Washington, D.C.

Csajbók, A., Csermely Á. (Eds.), 2002. Adopting the euro in Hungary: Expected costs, benefits and timing. NBH Occasional Working Papers, 24.

De Grauwe, P., 2002. Economics of Monetary Union. Oxford University Press, Fourth Edition.

Devereux, M.B., Gregory A., Smith G.W., 1992. Realistic cross-country consumption correlations in a two-country equilibrium business cycle model. Journal of International Money and Finance 11, 3-16.

Eichengreen, B., 1992. Should the Maastricht Treaty be saved?, Princeton Studies in International Finance 74.

Emerson, M., Gros D., Italianer A., Pisani-Ferry J., Reichenbach H., 1992. One market, one money. Oxford University Press

Fagan, G., Henry J., Mestre R., 2001. An area-wide model (AWM) for the euro area. ECB Working Paper 42.

Faust, J., Leeper E.M. 1997. When do long-run identifying restrictions give reliable results? Journal of Business and Economic Statistics 15 (3), 345-353.

Fidrmuc, J. 2001a. Intraindustry trade between the EU and the CEECs - The evidence of the first decade of transition. Focus on Transition 1/2001, 65-78.

Fidrmuc, J. 2001b. The endogeneity of the optimum currency area criteria, intraindustry trade, and EMU enlargement. BOFIT Discussion Paper 8/2001.

Fidrmuc, J., Korhonen I., 2004a. The euro goes east: Implications of the 2000-2002 slowdown for synchronization of business cycles between the euro area and CEECs. Comparative Economic Studies 46 (1), 45-62.

Fidrmuc, J., Korhonen, I., 2004b. Meta-analysis of the business cycle correlation between the euro area and the CEECs: What do we know? BOFIT Discussion Paper, Bank of Finland.

Fidrmuc, J., 2004. The endogeneity of the optimum currency area criteria, intra-industry trade, and EMU enlargement. Contemporary Economic Policy 22 (1), 1-12.

Fontagné, L., Freudenberg M., 1999. Endogenous symmetry of shocks in a Monetary Union. Open Economies Review 10 (3), 263-287.

Forni, M., Reichlin L., 1998. Lets get real: A factor analytical approach to disaggregated business cycle dynamics. Review of Economic Studies 65, 453-473.

Forni, M., Hallin M., Lippi M. Reichlin L., 2000. The generalized dynamic-factor model: Identification and estimation. The Review of Economics and Statistics, 82 (4), 540-554.

Frankel, J., 2004. Real convergence and euro adoption in Central and Eastern Europe: Trade and business cycle correlations as endogenous criteria for joining EMU. paper 
for Conference on Euro Adoption in the Accession Countries - Opportunities and Challenges, Czech National Bank, Prague, February 2-3, 2004.

Frankel, J.A., Rose A.K., 1998. The endogeneity of the optimum currency area criteria. The Economic Journal 108, 1009-1025.

Frankel, J.A., Rose A.K., 2002. An estimate of the effect of common currencies in trade and income. The Quarterly Journal of Economics, 437-466.

Frenkel, M., Nickel C., Schmidt G., 1999. Some shocking aspect of EMU enlargement. Deutsche Bank Research Note 99-4.

Gerlach, H.M.S., 1988. World business cycles under fixed and flexible exchange rates. Money Market and Banking 20 (4), 621-632.

Giannone, D., Reichlin L., Sala L., 2003. VARs, common factors and the empirical validation of equilibrium business cycle models. CEPR Discussion Paper 3701, Centre for Economic Policy Research, London

Glick, R., Rose A.K., 2001. Does currency union affect trade? The time series evidence, NBER Working Paper 8396.

Gregory, A.W., Head A.C., 1999. Common and country-specific fluctuations in productivity, Investment, and the Current Account. Journal of Monetary Economics, 44 (3), 423-451.

Gregory, A.W., Head A.C., Raynauld J., 1997. Measuring world business cycles. International Economic Review, 38 (3), 677-701.

Harvey, A.C., Jaeger, A., 1993. Detrending, stylized facts and the business cycle. Journal of Applied Econometrics 8, 231-47.

Head, A.C., 1995. Country size, aggregate fluctuations, and international risk sharing. The Canadian Journal of Economics 28 (4b), 1096-1119.

Helbling, T., Bayoumi T., 2003. Are they all in the same boat? The 2000-2001 growth slowdown and the G-7 business cycle linkages. IMF Working Paper 03/46.

HM Treasury, 2003. The Five Tests Framework.

Kalemli-Ozcan, S., Sorensen B.E., Yosha O., 2001. Economic integration, industrial specialization, and the asymmetry of macroeconomic fluctuations. Journal of International Economics 55 (1), 107- 37.

Kaufmann, S., 2003. The business cycle of European countries Bayesian clustering of country-individual IP growth series”, Oesterreichische Nationalbank, Working Paper 83.

Kenen, P.B., 1969. The optimum currency area: An eclectic view. In Mundell R.A., Swoboda A. (Eds.), Monetary Problems of the International Economy. University of Chicago Press, Chicago.

Kenen, P.B. 2002. Currency unions and trade: Variations on themes by Rose and Persson, Reserve Bank of New Zealand, Discussion Paper 2002/08, 1-34.

Korhonen, I. 2003. Some empirical tests on the integration of economic activity between the euro area and the accession countries. Economics of Transition 11 (1), 177-196.

Kose, A.A., Prasad E.S., Terrones M., 2003. How does globalization affect the synchronization of business cycles? The American Economic Review, Paper presented at the AEA 2003 meetings, Washington, D.C. 
Krugman, P., 1993. Lessons of Massachusetts for EMU. In Torres F., Giavazzi F. (Eds.), Adjustment and Growth in the European Union. Cambridge University Press, 241-261.

Lewis, K.K., 1996. What can explain the apparent lack of international consumption risk sharing? Journal of Political Economy 104, 267-97.

Lumsdaine, R.L., Prasad E.S., 1997. Identifying the common component on international economic fluctuations. NBER Working Paper 5984.

McKinnon, R., 1963. Optimum currency areas. The American Economic Review 53, (4), 717-725.

Micco, A., Stein E., Ordoñez G., 2003. The currency union effect on trade: Early evidence from EMU. Economic Policy, October, pp. 317-56.

Mitchell, J., Mouratidis K., 2003. Is there a common euro-zone business cycle? Working Papers and Studies, European Commission.

Monfort, A., Renne J.P., Rueffer R., Vitale G., 2003. Is economic activity in the G7 synchronized? Common shocks versus spillover effects. Paper presented at the AEA 2003 meetings, Washington, D.C.

Mongelli, F.P., 2002. New views on the optimum currency area theory: What is EMU telling us? ECB, Working Paper 138.

Mundell, R.A., 1961. A theory of optimum currency areas. The American Economic Review 51 (4), 657-665.

Obstfeld, M., Rogoff K., 1996. Foundations of International Macroeconomics, The MIT Press, Cambridge.

Obstfeld, M., Rogoff K., 2000. The six major puzzles in international macroeconomics: Is there a common cause? In NBER Macroeconomics Annual 2000, 339-390.

Persson, T., 2001. Currency unions and trade: How large is the treatment effect? Economic Policy, October 2001, (33), 433-448.

Pesaran, M.H., Shin Y., 1998. Impulse response analysis in linear multivariate models. Economics Letters 58, 17-29.

Rogoff, K., 2001. Why not a global currency? The American Economic Review, AEA Papers and Proceedings, 2001, 91 (2), 243-247.

Rose, A.K., 2002. The effect of common currencies on international trade: Where do we stand? Monetary Authority of Singapore Occasional Paper 22.

Rose, A.K., 2000. One money, one market: Estimating the effect of common currencies on trade, Economic Policy 30, 7-33.

Rose, A.K., van Wincoop E., 2001. National money as a barrier to international trade: The real case for currency union. American Economic Review 91, 386-90.

Stock, J.H., Watson M.O., 1998. Diffusion indexes, NBER Working Paper 6702.

Stock, J.H., Watson M.O.W., 1999. Business Cycle Fluctuations in US Macroeconomic Time Series. In: Talor J.B., Woodford M. (Eds.) Handbook of Macroeconomics 1. Elseiver Science B.V., 3-64.

Stockman, A.C., Tesar L.L., 1995. Tastes and technology in a two-country model of the business cycle: explaining international comovements. American Economic Review 85, 168-85. 
Tavlas, G.S., 1993. The 'New' theory of optimum currency areas. The World Economy, 663-685.

Várpalotai, V. 2003. Numerical method for estimating GDP data for Hungary. Magyar Nemzeti Bank Working Paper 2003/2.

\section{Data Appendix}

Our main data source is the OECD's Quarterly National Accounts database (January 2004 edition). Hence, data for sectoral components (i.e. industrial production and services) used in our paper are value added based. The table below lists the starting year of available data. Data from sources other than the OECD's database are underlined.

Starting year of available data

\begin{tabular}{|c|c|c|c|c|c|c|c|c|}
\hline Country name & $\begin{array}{l}\text { Country } \\
\text { code }\end{array}$ & GDP & $\begin{array}{l}\text { Private } \\
\text { consump } \\
\text { tion }\end{array}$ & $\begin{array}{l}\text { Investm } \\
\text { ent }\end{array}$ & Exports & Imports & $\begin{array}{l}\text { Indust. } \\
\text { prod. }\end{array}$ & Services \\
\hline \multicolumn{9}{|l|}{ CEECs } \\
\hline Czech Republic & CZE & $\underline{1993}$ & 1994 & 1994 & 1994 & 1994 & 1994 & 1994 \\
\hline Estonia & EST & $\underline{1993}$ & $\underline{1993}$ & $\underline{1993}$ & $\underline{1993}$ & $\underline{1993}$ & 1994 & n.a. \\
\hline Hungary & HUN & $\underline{1993}$ & $\underline{1993}$ & $\underline{1993}$ & $\underline{1993}$ & $\underline{1993}$ & 1995 & 1995 \\
\hline Latvia & LAT & $\underline{1993}$ & $\underline{1995}$ & $\underline{1995}$ & $\underline{1995}$ & $\underline{1995}$ & $\underline{1995}$ & n.a. \\
\hline Lithuania & LIT & $\overline{1993}$ & $\overline{1993}$ & $\overline{1993}$ & $\overline{1993}$ & $\overline{1993}$ & $\overline{\text { n.a. }}$ & n.a. \\
\hline Poland & POL & $\underline{1993}$ & 1995 & 1995 & 1995 & 1995 & 1995 & 1995 \\
\hline Slovak Republic & SKK & $\underline{1993}$ & $\underline{1993}$ & $\underline{1993}$ & $\underline{1993}$ & $\underline{1993}$ & 1994 & 1994 \\
\hline Slovenia & SLO & $\overline{1993}$ & $\overline{1999}$ & $\overline{1999}$ & $\overline{1999}$ & $\overline{1999}$ & $\overline{1993}$ & $\overline{1993}$ \\
\hline \multicolumn{9}{|l|}{ EMU } \\
\hline$\overline{\text { EMU-aggregate }}$ & EMU & $\underline{\boldsymbol{}}$ & $\underline{\boldsymbol{}}$ & $\underline{v}$ & $\underline{\boldsymbol{V}}$ & $\underline{v}$ & $\underline{1991}$ & $\underline{1991}$ \\
\hline Austria & AUT & $\checkmark$ & 1988 & 1988 & 1988 & 1988 & $\overline{1988}$ & $\overline{1988}$ \\
\hline Belgium & BEL & $\checkmark$ & $\checkmark$ & $\checkmark$ & $\checkmark$ & $\checkmark$ & $\checkmark$ & $\checkmark$ \\
\hline France & FRA & $\checkmark$ & $\checkmark$ & $\checkmark$ & $\checkmark$ & $\checkmark$ & $\checkmark$ & $\checkmark$ \\
\hline Finland & FIN & $\checkmark$ & $\checkmark$ & $\checkmark$ & $\checkmark$ & $\checkmark$ & $\checkmark$ & $\boldsymbol{V}$ \\
\hline Germany & GER & $\checkmark$ & 1991 & 1991 & 1991 & 1991 & 1991 & 1991 \\
\hline Ireland & IRE & 1997 & 1997 & 1997 & 1997 & 1997 & $\underline{\boldsymbol{}}$ & n.a. \\
\hline Italy & ITA & $\checkmark$ & $\checkmark$ & $\checkmark$ & $\checkmark$ & $\checkmark$ & $\boldsymbol{V}$ & $\checkmark$ \\
\hline Netherlands & NDL & $\checkmark$ & $\checkmark$ & $\checkmark$ & $\checkmark$ & $\checkmark$ & 1987 & 1987 \\
\hline Portugal & POR & $\underline{\boldsymbol{}}$ & 1995 & 1995 & 1995 & 1995 & 1995 & 1995 \\
\hline Spain & SPA & $\checkmark$ & $\checkmark$ & $\checkmark$ & $\checkmark$ & $\checkmark$ & $\checkmark$ & $\checkmark$ \\
\hline \multicolumn{9}{|l|}{ Control group } \\
\hline Denmark & DEN & 1988 & 1988 & 1988 & 1988 & 1988 & 1988 & 1988 \\
\hline Sweden & SWE & $\checkmark$ & $\checkmark$ & $\checkmark$ & $\checkmark$ & $\checkmark$ & $\checkmark$ & $\checkmark$ \\
\hline United Kingdom & UK & $\checkmark$ & $\checkmark$ & $\checkmark$ & $V$ & $\checkmark$ & $\checkmark$ & $\boldsymbol{V}$ \\
\hline Switzerland & SWI & $\checkmark$ & $\checkmark$ & $\checkmark$ & $\checkmark$ & $\checkmark$ & $\underline{V}$ & n.a. \\
\hline Norway & NOR & $\checkmark$ & $\checkmark$ & $\checkmark$ & $\checkmark$ & $\checkmark$ & $\checkmark$ & $\checkmark$ \\
\hline United States & USA & $\checkmark$ & $\checkmark$ & $\checkmark$ & $V$ & $\checkmark$ & $\underline{V}$ & $\underline{v}$ \\
\hline Japan & JAP & $\checkmark$ & $\checkmark$ & $V$ & $V$ & $V$ & $\underline{V}$ & n.a. \\
\hline Russia & RUS & $\underline{1993}$ & $\underline{1995}$ & $\underline{1995}$ & $\underline{1995}$ & $\underline{1995}$ & $\underline{1995}$ & $\underline{1995}$ \\
\hline
\end{tabular}

Notes. $\boldsymbol{V}$ : the series is available since 1980; n.a.: not available. Series underlined are taken (at least partly) from other sources than the OECD’s Quarterly National Accounts database. 


\section{Other sources:}

Czech Republic: quarterly national accounts are available from the OECD database since 1994Q1. For 1993, GDP data was calculated with the method of Várpalotai (2003).

EMU-aggregate: $4^{\text {th }}$ update (2003) of the ECB Area-Wide Model database for GDP and its expenditure components; see Fagan et al (2001). Value added of services and industrial production is from the ECB.

Estonia: The IMF - International Financial Statistics (IFS) database contains real GDP and nominal expenditure components. Consumption was deflated with CPI; investments, exports and imports were deflated with PPI. For industrial output only gross industrial output is available (source: Eesti Pank).

Greece: The only Greek data available at a quarterly frequency is gross industrial production, which is from the IFS.

Hungary: quarterly national accounts are available from the Hungarian Central Statistical Office since 1995Q1. For 1993-94, data were calculated by Várpalotai (2003).

Ireland: Gross industrial production is from the IFS.

Japan: Gross industrial production is from the IFS.

Latvia: The source of GDP and its expenditure components for 1995Q1-2003Q3 is the Central Statistical Bureau of Latvia (CSBL). GDP for 1993-1994 is taken from the IFS, which was chained back to CSBL data starting in 1995. For industrial output only gross industrial output is available (source: CSBL).

Lithuania: The IFS database contains real GDP and nominal expenditure components. Consumption was deflated with CPI; investments, exports and imports were deflated with PPI. The January 2004 issue of the IFS likely included measurement errors for real GDP as it indicated an annual real growth rate of around 40 percent in 1994. Therefore, we chained the data for 1993-94 as it was included in the November 2003 edition with data for 1995-2003 included in the January 2004 edition.

Poland: quarterly national accounts are available from 1995Q1 to 2002Q2 in the OECD dataset. Data for 2002Q3-Q4 (and some quarters in 2003) are from the dX Econdata of Emerging Market Economic Data Ltd. Quarterly GDP data for 1993-94 were calculated with the method of Várpalotai (2003).

Portugal: quarterly national accounts are available in the OECD database since 1995. Pre-1995 GDP data are from the IFS.

Russia: dX Econdata of Emerging Market Economic Data Ltd (January 2004 edition) for 1995-2003. GDP data for 1993-94 were calculated with the method of Várpalotai (2003).

Slovak Republic: dX Econdata of Emerging Market Economic Data Ltd (January 2004 edition).

Slovenia: Bank of Slovenia.

Switzerland: Gross industrial production is from the IFS.

United States: Services - US Department of Commerce, Bureau of Economic Analysis. Gross industrial production is from the IFS. 
Table 1: Summary Table of Correlation, 1993-2002

\section{3-1997}

\begin{tabular}{|c|c|c|c|c|c|c|c|c|c|c|}
\hline & & EMU1 & EMU2 & OUTS & USA & JAP & RUS & CEE1 & CEE2 & CEE3 \\
\hline \multirow{4}{*}{ ڤิ } & AG-HP & 0.72 & 0.54 & 0.71 & 0.27 & 0.04 & -0.60 & 0.19 & 0.43 & -0.29 \\
\hline & $\mathrm{AG}$ & 82 & .74 & .78 & -0.17 & 0.08 & -0.47 & 0.17 & 0.39 & -0.3 \\
\hline & CF-HP & 0.61 & 0.38 & 0.60 & 0.52 & -0.31 & -0.54 & 0.26 & 0.05 & -0.06 \\
\hline & CF-BP & 0.75 & 0.55 & 0.73 & 0.22 & -0.27 & -0.63 & 0.24 & 0.11 & -0.25 \\
\hline \multirow{2}{*}{ 吕 } & AG-HP & & & & & 0.5 & 0.72 & 0.42 & -0.14 & 0.2 \\
\hline & AG-BP & 86 & .28 & .71 & 0.08 & 0.45 & 0.76 & .24 & 0.18 & -0.06 \\
\hline & AG-HP & .77 & 0.50 & 0.54 & 0.58 & 0.36 & 0.14 & -0.21 & 0.38 & -0.07 \\
\hline & AG-BP & 0.79 & 0.31 & 0.51 & 0.64 & 0.22 & 0.23 & -0.19 & 0.34 & -0.18 \\
\hline & AG-HP & 0.87 & 0.84 & 0.67 & 0.54 & 0.32 & -0.43 & -0.41 & -0.17 & -0.33 \\
\hline & AG-BP & 0.89 & 0.83 & 0.58 & 0.09 & 0.27 & -0.49 & -0.41 & -0.23 & -0.53 \\
\hline & AG-HP & & 0.09 & -0.22 & 0.34 & & 0.04 & 0.07 & 0.25 & \\
\hline & AG-BP & 0.42 & 0.50 & 0.44 & 0.07 & & -0.32 & 0.02 & 0.18 & \\
\hline & AG-HP & & & & & 0.07 & -0.03 & -0.25 & -0.23 & -0.33 \\
\hline & AG-BP & 0.58 & 0.66 & 0.41 & 0.05 & 0.19 & -0.32 & -0.35 & -0.35 & -0.52 \\
\hline & AG-HP & 0.52 & 0.46 & 060 & & 025 & 0.16 & -0.19 & -0.01 & -0.1 \\
\hline & AG-BP & 0.57 & 0.42 & 0.63 & -0.17 & 0.11 & 0.44 & -0.29 & -0.13 & -0.17 \\
\hline
\end{tabular}

AG: using aggregate euro area data; CF: using the common factor; HP: Hordick-Prescott filter; BP: Band-Pass filter

EMU1: Austria, Belgium, France, Germany, Italy, Netherlands; EMU2: Finland, Portugal, Spain, OUTS: Denmark, Sweden, Switzerland (not in services), UK; CEE1: Hungary, Poland, Slovenia (only in GDP, industry, and services); CEE2: Czech Republic, Slovakia; CEE3: Estonia, Latvia, Lithuania (not in industry)

\section{8-2002}

\begin{tabular}{|c|c|c|c|c|c|c|c|c|c|c|}
\hline & & EMU1 & EMU2 & OUTS & USA & JAP & RUS & CEE1 & CEE2 & CEE3 \\
\hline \multirow{4}{*}{ ڤิ } & AG-HP & 0.91 & 0.71 & 0.82 & 0.73 & 0.54 & 0.39 & 0.73 & -0.34 & -0.33 \\
\hline & AG-BP & 88 & .51 & 0.65 & 0.68 & 0.73 & 0.53 & 0.71 & -0.16 & -0.2 \\
\hline & CF-HP & 0.82 & 0.71 & 0.76 & 0.81 & 0.31 & 0.24 & 0.71 & -0.31 & -0.33 \\
\hline & CF-BP & 0.78 & 0.52 & 0.46 & 0.77 & 0.49 & 0.36 & 0.71 & -0.25 & -0.2 \\
\hline \multirow{2}{*}{ ت્ } & & 0.85 & & 0.64 & 0.67 & 0.62 & $\overline{0.16}$ & 0.76 & 0.16 & 0.2 \\
\hline & AG-BP & 0.82 & .59 & 48 & 44 & 0.66 & 0.26 & 0.67 & 0.29 & \\
\hline \multirow{2}{*}{$\underset{\substack{x \\
\mid I}}{\dot{a}}$} & AG-HP & 0.92 & 0.78 & 0.80 & 0.86 & 0.59 & -0.03 & 0.79 & 0.64 & 0.2 \\
\hline & AG-BP & 0.90 & 0.73 & 0.73 & 0.84 & 0.67 & 0.00 & 0.80 & 0.63 & 0.3 \\
\hline \multirow{2}{*}{$\dot{\vec{\Xi}}$} & AG-HP & 0.91 & 0.77 & 0.91 & 0.89 & 0.47 & -0.16 & 0.50 & 0.23 & $\overline{-0.0}$ \\
\hline & AG-BP & 0.85 & 0.61 & 0.81 & 0.84 & 0.56 & 0.13 & 0.48 & 0.34 & -0.0 \\
\hline \multirow{2}{*}{$\vec{d}^{\dot{0}}$} & AG-HP & 0.86 & 0.78 & 0.63 & 0.65 & & 0.16 & 0.24 & -0.67 & \\
\hline & AG-BP & 0.79 & 0.58 & 0.48 & 0.59 & & 0.48 & 0.19 & -0.65 & \\
\hline \multirow{2}{*}{ טే } & AG-HP & 0.82 & 0.65 & 0.47 & 0.74 & -0.47 & -0.68 & -0.12 & -0.54 & -0.2 \\
\hline & AG-BP & 0.73 & 0.41 & 0.21 & 0.57 & -0.09 & -0.62 & 0.03 & -0.47 & -0.2 \\
\hline \multirow{2}{*}{ 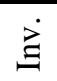 } & AG-HP & 0.85 & 0.64 & 0.60 & 0.91 & 0.63 & 0.07 & 0.24 & -0.40 & $\overline{-0.4}$ \\
\hline & AG-BP & 0.75 & 0.23 & 0.30 & 0.93 & 0.64 & 0.33 & 0.22 & -0.35 & -0.5 \\
\hline
\end{tabular}

AG: using aggregate euro area data; CF: using the common factor; HP: Hordick-Prescott filter; BP: Band-Pass filter

EMU: Austria, Belgium, France, Germany, Italy, Netherlands; EMU2: Finland, Ireland (not in industry and services), Portugal, Spain, OUTS: Denmark, Sweden, Switzerland (not in services), UK; CEE1: Hungary, Poland, Slovenia; CEE2: Czech Republic, Slovakia; CEE3: Estonia, Latvia, Lithuania (not in industry) 
Table 2: Summary Table of the Absolute Value of Leads/Lags*, 1993-2002

\section{3-1997}

\begin{tabular}{|c|c|c|c|c|c|c|c|c|c|c|}
\hline & & EMU1 & EMU2 & OUTS & USA & JAP & RUS & CEE1 & CEE2 & CEE3 \\
\hline \multirow{4}{*}{ 仓े } & AG-HP & 0.17 & 0.67 & 0.75 & 2.00 & 2.00 & 3.00 & 1.33 & 0.50 & 3.00 \\
\hline & AG-BP & 0.17 & 0.67 & 1.00 & 3.00 & 3.00 & 3.00 & 1.67 & 1.50 & 3.00 \\
\hline & CF-HP & 0.33 & 0.00 & 0.00 & 0.00 & 3.00 & 3.00 & 2.00 & 1.00 & 2.67 \\
\hline & CF-BP & 0.00 & 0.00 & 0.75 & 3.00 & 3.00 & 3.00 & 1.33 & 1.00 & 2.67 \\
\hline \multirow{2}{*}{ ذ્छ } & AG-HP & 0.17 & 1.33 & 0.50 & 1.00 & 0.00 & 1.00 & 2.00 & 3.00 & 1.50 \\
\hline & AG-BP & 0.17 & 1.67 & 0.75 & 3.00 & 1.00 & 1.00 & 2.00 & 3.00 & 2.50 \\
\hline \multirow{2}{*}{$\underset{\substack{x \\
\mid}}{\dot{x}}$} & AG-HP & 0.17 & 0.67 & 0.25 & 0.00 & 0.00 & 3.00 & 2.50 & 1.50 & 2.33 \\
\hline & AG-BP & 0.17 & 1.67 & 0.50 & 0.00 & 0.00 & 3.00 & 2.00 & 2.00 & 3.00 \\
\hline \multirow{2}{*}{ 官 } & AG-HP & 0.00 & 0.00 & 0.75 & 2.00 & 1.00 & 3.00 & 3.00 & 3.00 & 3.00 \\
\hline & AG-BP & 0.00 & 1.00 & 1.25 & 3.00 & 2.00 & 3.00 & 3.00 & 3.00 & 3.00 \\
\hline \multirow{2}{*}{$\sum_{\infty}^{\infty}$} & AG-HP & 1.50 & 2.00 & 1.00 & 3.00 & & 3.00 & 1.33 & 2.50 & \\
\hline & AG-BP & 1.33 & 1.67 & 1.00 & 3.00 & & 3.00 & 1.67 & 2.50 & \\
\hline \multirow{2}{*}{ ڤే } & AG-HP & 1.00 & 0.33 & 2.50 & 3.00 & 0.00 & 3.00 & 3.00 & 3.00 & 2.67 \\
\hline & AG-BP & 0.83 & 0.00 & 1.75 & 3.00 & 2.00 & 3.00 & 3.00 & 3.00 & 3.00 \\
\hline & AG-HP & 0.33 & 0.33 & 0.75 & 1.00 & 2.00 & 2.00 & 2.50 & 2.50 & 3.00 \\
\hline & AG-BP & 0.67 & 1.33 & 1.25 & 3.00 & 3.00 & 2.00 & 2.50 & 2.50 & 3.00 \\
\hline
\end{tabular}

AG: using aggregate euro area data; CF: using the common factor; HP: Hordick-Prescott filter; BP: Band-Pass filter

\section{8-2002}

\begin{tabular}{|c|c|c|c|c|c|c|c|c|c|c|}
\hline & & EMU1 & EMU2 & OUTS & USA & JAP & RUS & CEE1 & CEE2 & CEE3 \\
\hline \multirow{4}{*}{ ڤิ } & AG-HP & 0.33 & 0.25 & 0.25 & 2.00 & 1.00 & 1.00 & 0.67 & 3.00 & 2.33 \\
\hline & AG-BP & 0.50 & 1.00 & 0.50 & 2.00 & 1.00 & 0.00 & 1.00 & 3.00 & 1.67 \\
\hline & CF-HP & 0.50 & 0.00 & 0.50 & 0.00 & 2.00 & 1.00 & 0.33 & 3.00 & 2.00 \\
\hline & CF-BP & 0.67 & 1.00 & 1.00 & 0.00 & 2.00 & 0.00 & 0.33 & 3.00 & 1.67 \\
\hline \multirow{2}{*}{ 灾 } & AG-HP & 0.17 & 0.33 & 1.00 & 1.00 & 1.00 & 2.00 & 0.67 & 1.00 & 1.00 \\
\hline & AG-BP & 0.17 & 0.67 & 1.25 & 1.00 & 1.00 & 2.00 & 0.67 & 1.00 & 1.00 \\
\hline \multirow{2}{*}{$\dot{\vec{x}} \vec{x}$} & AG-HP & 0.00 & 0.25 & 0.75 & 1.00 & 1.00 & 3.00 & 0.00 & 1.00 & 1.33 \\
\hline & AG-BP & 0.00 & 0.25 & 0.50 & 1.00 & 1.00 & 3.00 & 0.00 & 0.50 & 1.33 \\
\hline \multirow{2}{*}{ 囩 } & AG-HP & 0.17 & 0.50 & 0.00 & 1.00 & 0.00 & 3.00 & 0.33 & 1.50 & 1.67 \\
\hline & AG-BP & 0.00 & 1.00 & 0.00 & 1.00 & 0.00 & 1.00 & 1.00 & 1.00 & 2.00 \\
\hline \multirow{2}{*}{ 定 } & AG-HP & 0.50 & 0.67 & 1.33 & 2.00 & & 3.00 & 2.33 & 3.00 & \\
\hline & AG-BP & 0.67 & 1.00 & 1.33 & 2.00 & & 1.00 & 2.33 & 3.00 & \\
\hline \multirow{2}{*}{ Ũ } & AG-HP & 0.83 & 1.75 & 0.75 & 1.00 & 3.00 & 3.00 & 2.67 & 3.00 & 3.00 \\
\hline & AG-BP & 0.67 & 1.00 & 2.50 & 2.00 & 3.00 & 3.00 & 2.00 & 3.00 & 3.00 \\
\hline & AG-HP & 0.17 & 0.75 & 0.75 & 1.00 & 2.00 & 3.00 & 2.67 & 3.00 & 2.67 \\
\hline & AG-BP & 0.50 & 2.50 & 2.00 & 1.00 & 2.00 & 3.00 & 2.67 & 3.00 & 2.67 \\
\hline
\end{tabular}

AG: using aggregate euro area data; CF: using the common factor; HP: Hordick-Prescott filter; BP: Band-Pass filter

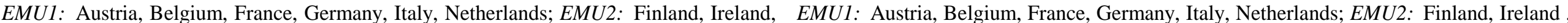

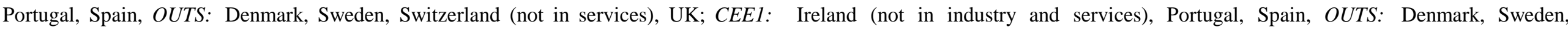

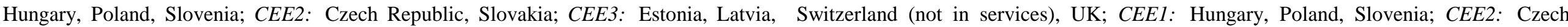
Lithuania (not in industry)

Republic, Slovakia; CEE3: Estonia, Latvia, Lithuania (not in industry)

* The table shows the group-specific mean of the absolute value of the leads/lags, since the mean of raw data could cancel out positive and negative values. The maximum leads/lags studied is 3 quarters. 
Table 3: Summary Table of Relative Volatility*, 1993-2002

\section{3-1997}

\begin{tabular}{|c|c|c|c|c|c|c|c|c|c|c|}
\hline & & EMU1 & EMU2 & OUTS & USA & JAP & RUS & CEE1 & CEE2 & CEE3 \\
\hline \multirow{2}{*}{ 仓े } & HP & 111 & 188 & 147 & 72 & 176 & 397 & 155 & 175 & 436 \\
\hline & BP & 113 & 144 & 153 & 112 & 210 & 420 & 177 & 188 & 489 \\
\hline \multirow{2}{*}{ ذ્ఏ } & HP & 121 & 120 & 151 & 57 & 181 & 132 & 128 & 301 & 232 \\
\hline & BP & 118 & 110 & 151 & 66 & 171 & 133 & 131 & 288 & 267 \\
\hline \multirow{2}{*}{$\underset{\substack{x \\
\text { |்̇ }}}{\dot{x}}$} & HP & 120 & 118 & 109 & 126 & 146 & 137 & 379 & 191 & 406 \\
\hline & BP & 123 & 139 & 107 & 78 & 178 & 133 & 400 & 217 & 453 \\
\hline \multirow{2}{*}{$\dot{\vec{\Xi}}$} & HP & 100 & 130 & 93 & 54 & 201 & 358 & 244 & 189 & 306 \\
\hline & BP & 109 & 140 & 100 & 106 & 239 & 454 & 261 & 219 & 386 \\
\hline \multirow{2}{*}{ 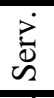 } & $\mathrm{HP}$ & 211 & 436 & 270 & 106 & & 461 & 204 & 1067 & \\
\hline & BP & 275 & 604 & 522 & 171 & & 907 & 326 & 1900 & \\
\hline \multirow{2}{*}{ 苛 } & HP & 120 & 210 & 134 & 66 & 131 & 401 & 285 & 332 & 676 \\
\hline & BP & 135 & 218 & 166 & 152 & 192 & 578 & 328 & 443 & 1002 \\
\hline \multirow{2}{*}{$\stackrel{\Xi}{ }$} & $\mathrm{HP}$ & 116 & 221 & 181 & 47 & 144 & 454 & 279 & 331 & 352 \\
\hline & BP & 126 & 222 & 207 & 117 & 161 & 638 & 356 & 394 & 451 \\
\hline
\end{tabular}

HP: Hordick-Prescott filter; BP: Band-Pass filter

EMU1: Austria, Belgium, France, Germany, Italy, Netherlands; EMU2: Finland, Portugal, Spain, OUTS: Denmark, Sweden, Switzerland (not in services), UK; CEE1: Hungary, Poland, Slovenia (only in GDP, industry, and services); CEE2: Czech Republic, Slovakia; CEE3: Estonia, Latvia, Lithuania (not in industry)

$* \mathrm{EMU}=100$

\section{8-2002}

\begin{tabular}{|c|c|c|c|c|c|c|c|c|c|c|}
\hline & & EMU1 & EMU2 & OUTS & USA & JAP & RUS & CEE1 & CEE2 & CEE3 \\
\hline \multirow{2}{*}{ Оิ } & HP & 121 & 179 & 102 & 145 & 139 & 457 & 124 & 168 & 265 \\
\hline & BP & 134 & 174 & 123 & 162 & 202 & 464 & 153 & 222 & 426 \\
\hline \multirow{2}{*}{ Ф્త } & HP & 129 & 152 & 204 & 219 & 300 & 413 & 201 & 303 & 394 \\
\hline & $\mathrm{BP}$ & 138 & 150 & 229 & 188 & 370 & 471 & 233 & 387 & 454 \\
\hline \multirow{2}{*}{$\underset{\substack{x \\
\text { 文 }}}{\dot{x}}$} & HP & 103 & 128 & 119 & 138 & 148 & 131 & 202 & 128 & 276 \\
\hline & BP & 106 & 132 & 124 & 147 & 176 & 144 & 219 & 153 & 328 \\
\hline \multirow{2}{*}{$\dot{\vec{\Xi}}$} & HP & 95 & 134 & 102 & 132 & 116 & 480 & 141 & 142 & 250 \\
\hline & BP & 104 & 149 & 103 & 160 & 181 & 596 & 164 & 194 & 337 \\
\hline \multirow{2}{*}{ 定 } & HP & 133 & 154 & 125 & 64 & & 359 & 99 & 386 & \\
\hline & BP & 147 & 138 & 142 & 82 & & 406 & 126 & 501 & \\
\hline \multirow{2}{*}{ ర̃ } & HP & 117 & 230 & 121 & 99 & 68 & 482 & 151 & 224 & 286 \\
\hline & BP & 126 & 279 & 139 & 118 & 79 & 550 & 214 & 317 & 411 \\
\hline \multirow{2}{*}{$\dot{\vec{\Xi}}$} & HP & 109 & 178 & 120 & 140 & 97 & 336 & 226 & 248 & 464 \\
\hline & BP & 126 & 198 & 128 & 167 & 158 & 484 & 325 & 383 & 70 \\
\hline
\end{tabular}

HP: Hordick-Prescott filter; BP: Band-Pass filter

1: Austria, Belgium, France, Germany, Italy, Netherlands; EMU2: Finland, Ireland (not in industry and services), Portugal, Spain, OUTS: Denmark, Sweden, Switzerland (not in services), UK; CEE1: Hungary, Poland, Slovenia; CEE2: Czech Republic, Slovakia; CEE3: Estonia, Latvia, Lithuania (not in industry) 
Table 4: Summary Table of Persistence, 1993-2002

1993-1997

1998-2002

\begin{tabular}{|c|c|c|c|c|c|c|c|c|c|c|}
\hline & & EMU1 & EMU2 & OUTS & USA & JAP & RUS & CEE1 & CEE2 & CEE3 \\
\hline \multirow{2}{*}{ ڤิ } & HP & 0.56 & 0.60 & 0.77 & 0.65 & 0.87 & 0.88 & 0.26 & 0.84 & 0.49 \\
\hline & BP & 0.65 & 0.69 & 0.79 & 0.88 & 0.89 & 0.84 & 0.29 & 0.83 & 0.49 \\
\hline \multirow{2}{*}{ Ð્త } & HP & 0.80 & 0.76 & 0.69 & 0.82 & 0.91 & 0.59 & 0.60 & 0.54 & 0.48 \\
\hline & BP & 0.82 & 0.72 & 0.73 & 0.90 & 0.91 & 0.52 & 0.58 & 0.51 & 0.64 \\
\hline \multirow{2}{*}{$\underset{\substack{x \\
\text { | }}}{\dot{y}}$} & HP & 0.64 & 0.31 & 0.70 & 0.84 & 0.82 & 0.50 & 0.06 & 0.41 & 0.79 \\
\hline & BP & 0.67 & 0.37 & 0.64 & 0.60 & 0.86 & 0.41 & 0.04 & 0.46 & 0.81 \\
\hline \multirow{2}{*}{ 官 } & HP & 0.63 & 0.63 & 0.69 & 0.79 & 0.96 & 0.54 & 0.53 & 0.42 & 0.68 \\
\hline & BP & 0.68 & 0.61 & 0.61 & 0.92 & 0.96 & 0.41 & 0.45 & 0.27 & 0.72 \\
\hline \multirow{2}{*}{ 悹 } & HP & 0.65 & 0.76 & 0.70 & 0.42 & & -0.07 & 0.19 & -0.08 & \\
\hline & BP & 0.55 & 0.78 & 0.73 & 0.64 & & 0.05 & 0.06 & -0.04 & \\
\hline \multirow{2}{*}{ 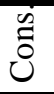 } & HP & 0.43 & 0.63 & 0.59 & 0.78 & 0.32 & 0.64 & 0.65 & 0.61 & 0.23 \\
\hline & $\mathrm{BP}$ & 0.51 & 0.66 & 0.65 & 0.93 & 0.41 & 0.68 & 0.55 & 0.60 & 0.36 \\
\hline \multirow{2}{*}{$\grave{\Xi}$} & HP & 0.33 & 0.75 & 0.68 & 0.48 & 0.87 & 0.01 & 0.45 & 0.80 & 0.28 \\
\hline & BP & 0.35 & 0.74 & 0.68 & 0.90 & 0.85 & 0.12 & 0.43 & 0.76 & 0.32 \\
\hline
\end{tabular}

\begin{tabular}{|c|c|c|c|c|c|c|c|c|c|c|}
\hline & & EMU1 & EMU2 & OUTS & $\overline{\mathrm{USA}}$ & JAP & $\overline{\text { RUS }}$ & CEE1 & CEE2 & CEE3 \\
\hline \multirow{2}{*}{ ڤิ } & HP & 0.83 & 0.63 & 0.65 & 0.88 & 0.72 & 0.81 & 0.59 & 0.80 & 0.71 \\
\hline & BP & 0.78 & 0.34 & 0.67 & 0.83 & 0.74 & 0.69 & 0.56 & 0.78 & 0.79 \\
\hline \multirow{2}{*}{ ذ્ધ } & HP & 0.70 & 0.65 & 0.57 & 0.94 & 0.80 & 0.73 & 0.73 & 0.30 & 0.77 \\
\hline & BP & 0.69 & 0.52 & 0.61 & 0.89 & 0.81 & 0.72 & 0.73 & 0.36 & 0.78 \\
\hline \multirow{2}{*}{$\underset{\substack{x \\
\text { 离 }}}{\dot{2}}$} & $\mathrm{HP}$ & 0.79 & 0.61 & 0.72 & 0.85 & 0.75 & 0.34 & 0.53 & 0.57 & 0.80 \\
\hline & BP & 0.76 & 0.53 & 0.70 & 0.82 & 0.77 & 0.32 & 0.50 & 0.61 & 0.81 \\
\hline \multirow{2}{*}{$\dot{\vec{\Xi}}$} & HP & 0.80 & 0.71 & 0.79 & 0.90 & 0.80 & 0.78 & 0.24 & 0.69 & 0.74 \\
\hline & BP & 0.75 & 0.61 & 0.70 & 0.88 & 0.84 & 0.77 & 0.30 & 0.72 & 0.75 \\
\hline \multirow{2}{*}{$\sum_{\omega}^{\infty}$} & HP & 0.81 & 0.85 & 0.62 & 0.78 & & 0.76 & 0.34 & 0.46 & \\
\hline & BP & 0.77 & 0.67 & 0.62 & 0.78 & & 0.71 & 0.28 & 0.44 & \\
\hline \multirow{2}{*}{ 苂 } & HP & 0.84 & 0.53 & 0.73 & 0.86 & 0.56 & 0.80 & 0.34 & 0.76 & 0.28 \\
\hline & BP & 0.77 & 0.25 & 0.67 & 0.83 & 0.40 & 0.75 & 0.42 & 0.77 & 0.33 \\
\hline \multirow{2}{*}{$\stackrel{\Xi}{ }$} & HP & 0.69 & 0.63 & 0.78 & 0.95 & 0.80 & 0.64 & 0.05 & 0.72 & 0.56 \\
\hline & BP & 0.52 & 0.41 & 0.64 & 0.92 & 0.80 & 0.62 & 0.11 & 0.76 & 0.56 \\
\hline
\end{tabular}

HP: Hordick-Prescott filter; BP: Band-Pass filter

HP: Hordick-Prescott filter; BP: Band-Pass filter

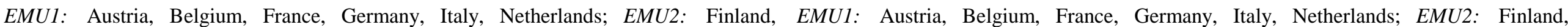

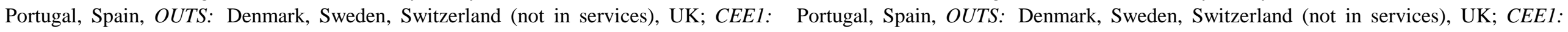

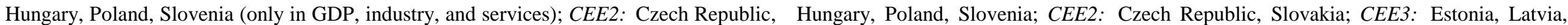
Slovakia; CEE3: Estonia, Latvia, Lithuania (not in industry). 
Table 5: International Investment Positions, 1993-2002 (percent of GDP)

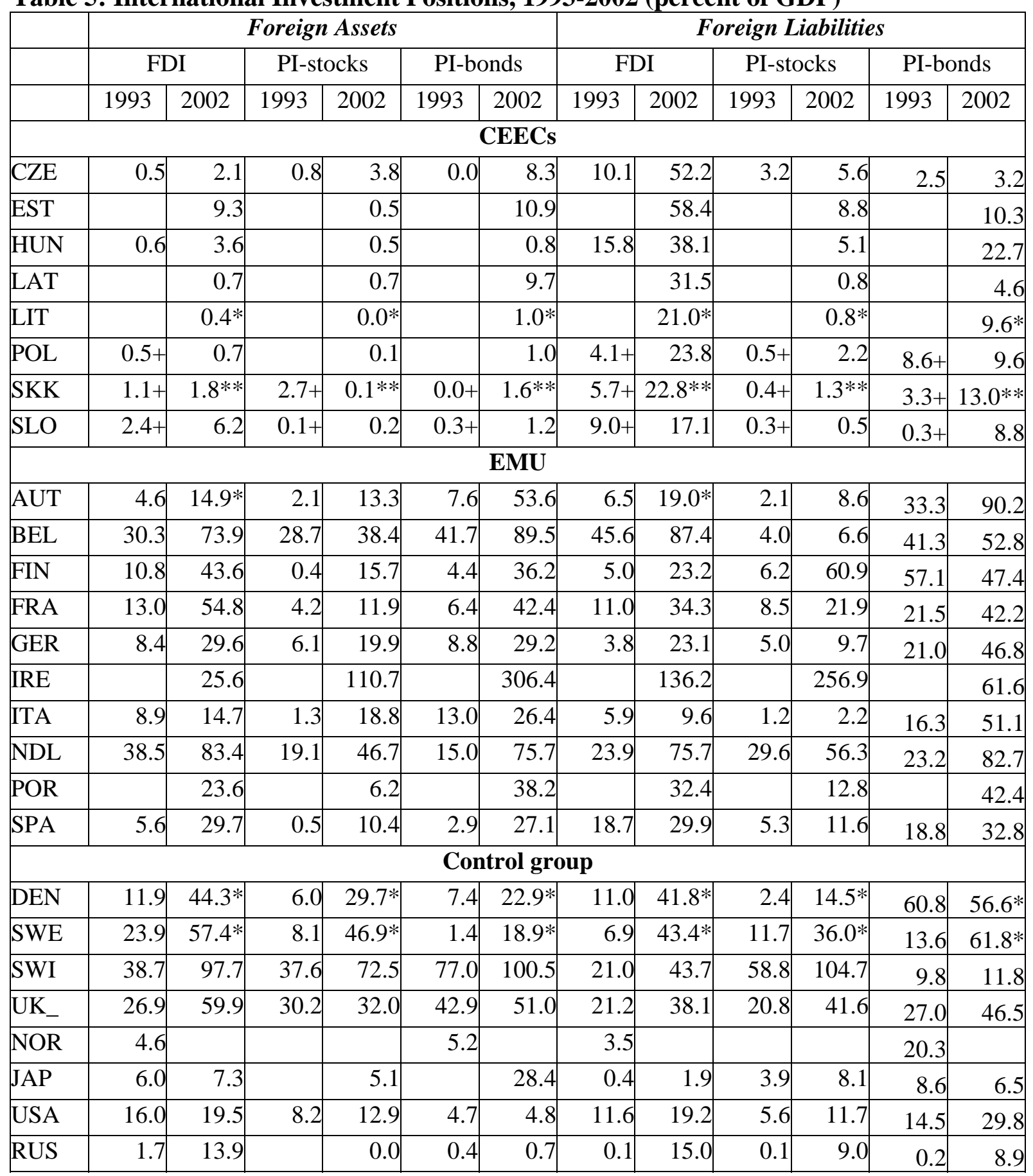

FDI: foreign direct investment, PI: portfolio investment. Source: Authors' calculation based on IMFInternational Financial Statistics. *: 2001, **:2000, +: 1994 
Figure 1/a: GDP - Correlation with the Cycle of EMU Aggregate, 1983-2002
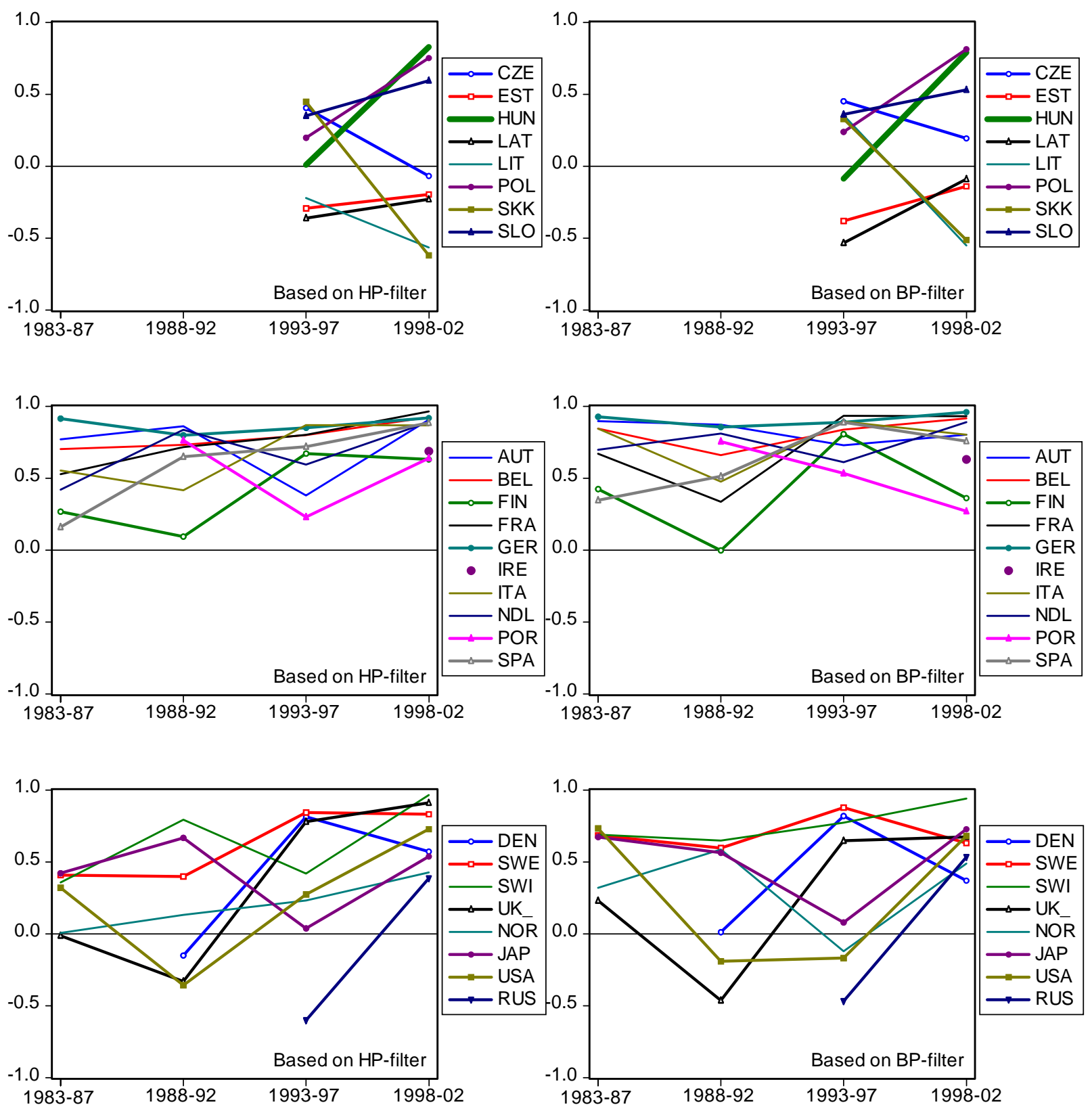
Figure 1/b: GDP - Correlation with the Cycle of EMU-5 Common Factor, 1983-2002
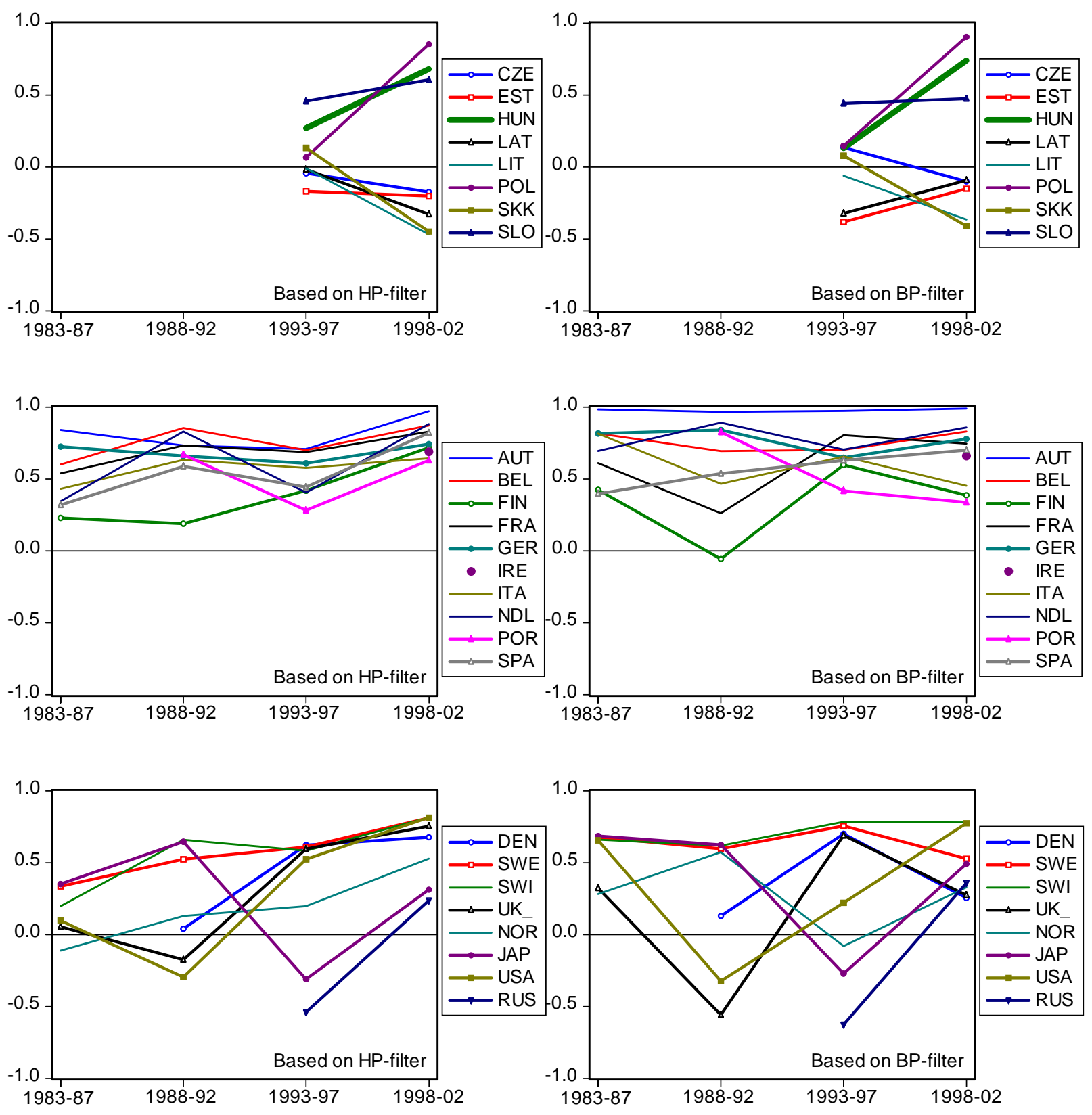
Figure 2/a: GDP - Correlation of CEECs with the Cycles of Russia and the EMU, 1993-2002

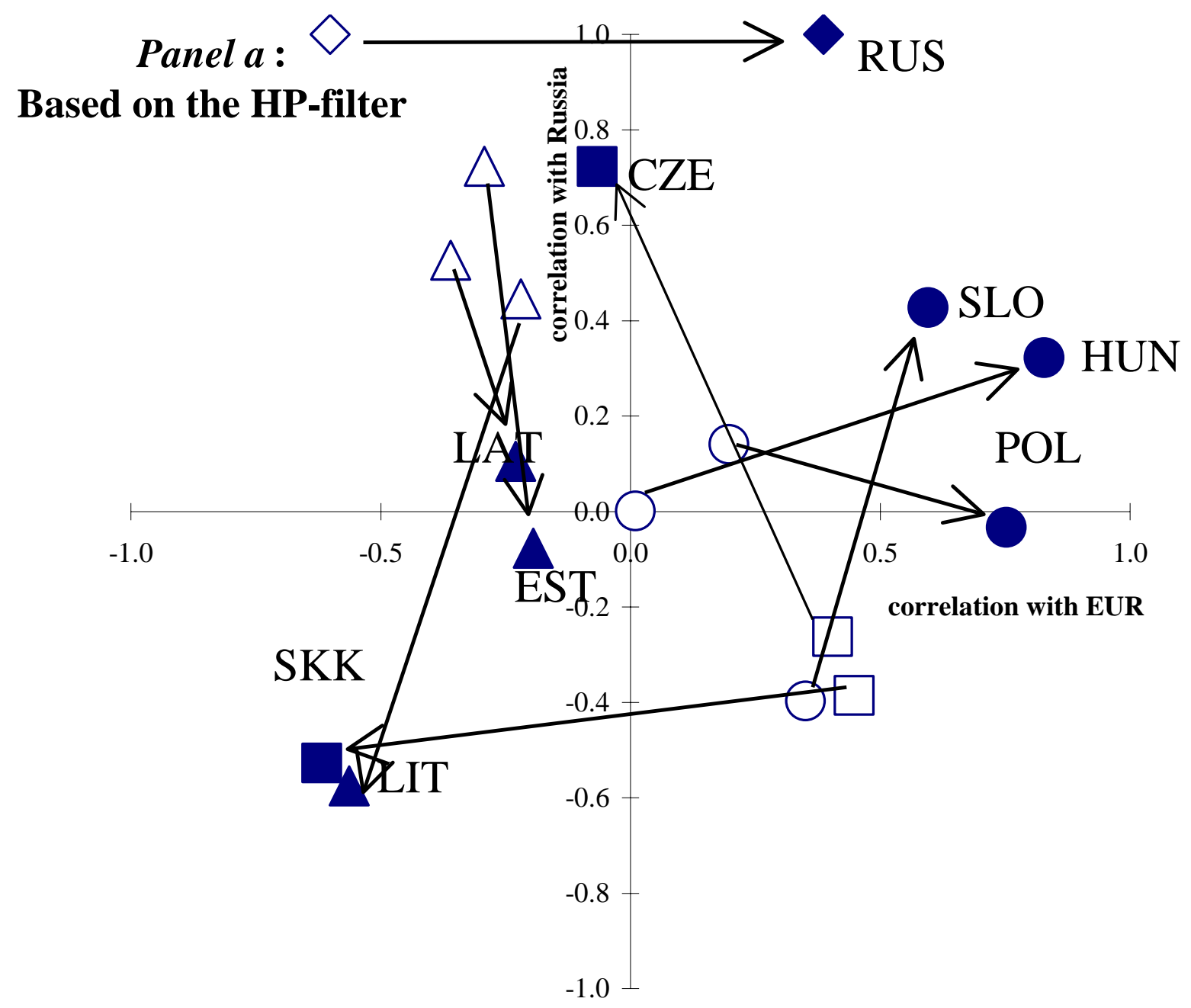

Notes: Empty symbols indicate values for 1993-97, while filled symbols for 1998-2002. The three Baltic states are denoted with triangles, the Czech Republic and Slovakia with squares, and Hungary, Poland and Slovenia with circles. 
Figure 2/b: GDP - Correlation of CEECs with the Cycles of Russia and the EMU, 1993-2002

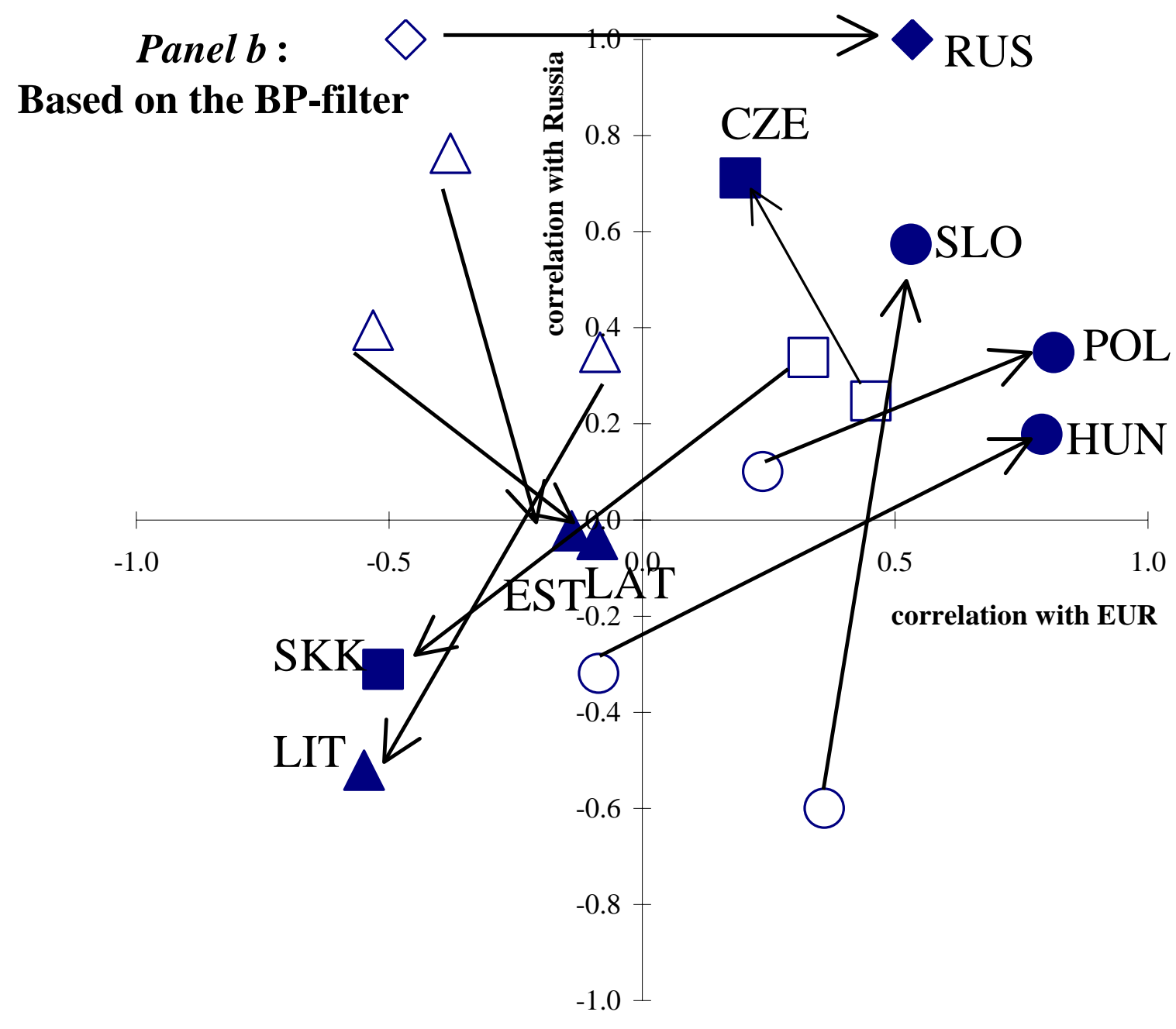

Notes: Empty symbols indicate values for 1993-97, while filled symbols for 1998-2002. The three Baltic states are denoted with triangles, the Czech Republic and Slovakia with squares, and Hungary, Poland and Slovenia with circles. 
Figure 3: GDP - Relative Impact of the EMU-5 Common Factor*, 1993-2002

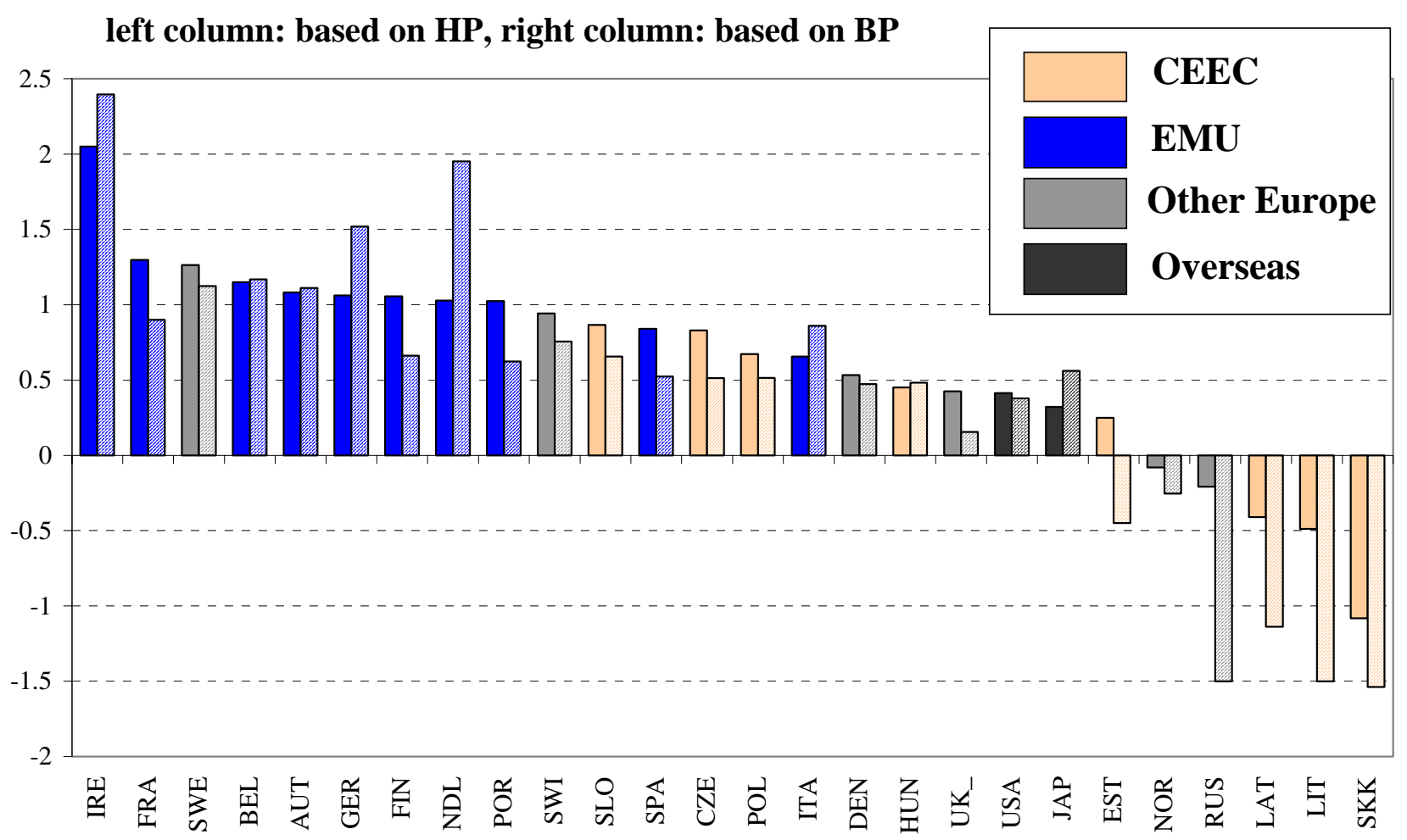

* Accumulated response up to six quarters to a common factor impulse divided by the response of the EMU-aggregate. 
Figure 4: The Consumption-Correlation Puzzle: Correlation of Consumption Less Correlation of GDP

Panel $a$ : Based on HP-filter, left column: 1993-97, right column: 1998-02

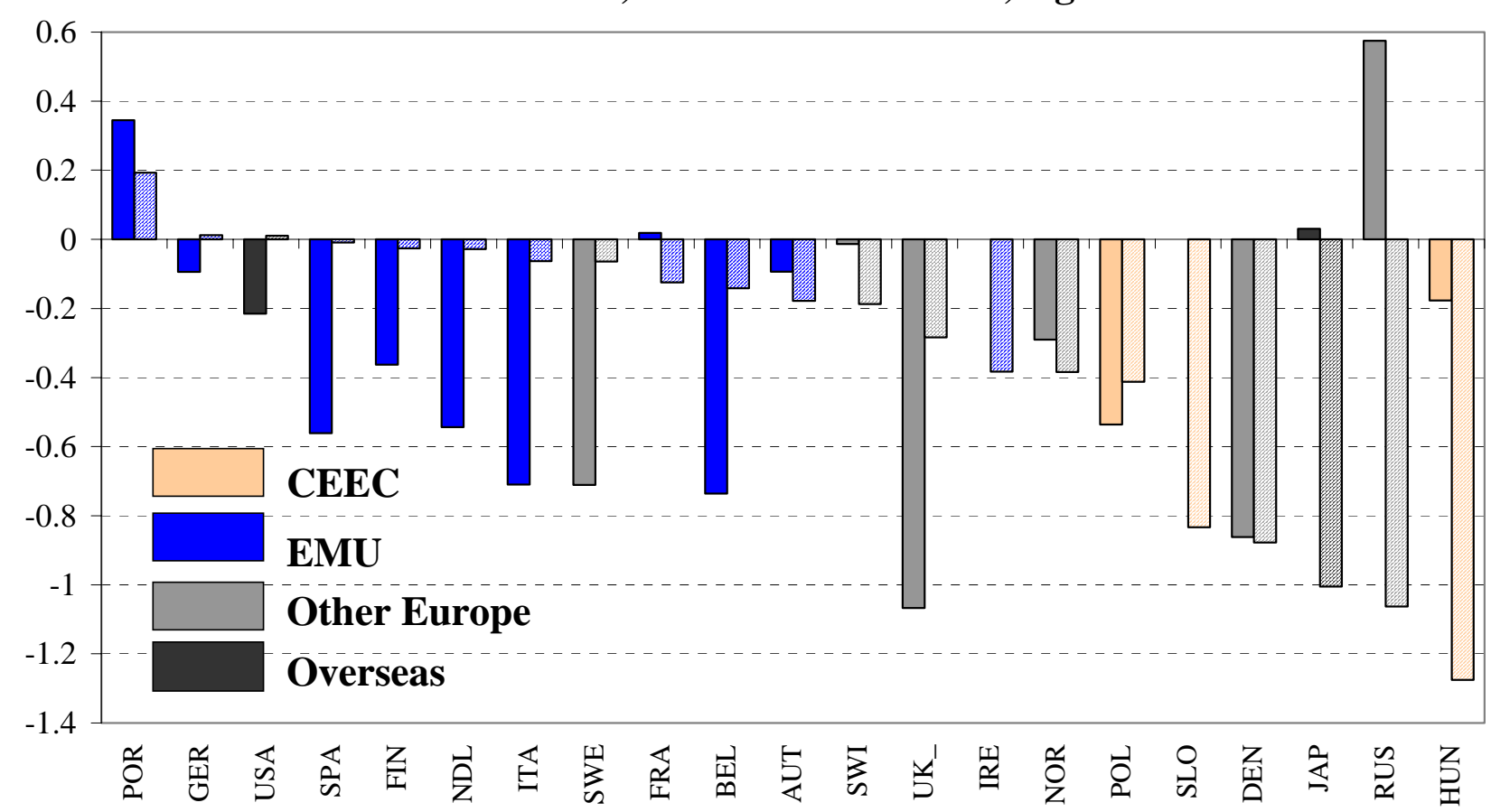

Note: no data is available for Ireland and Slovenia in 1993-97.

Panel b : Based on BP-filter, left column: 1993-97, right column: 1998-02

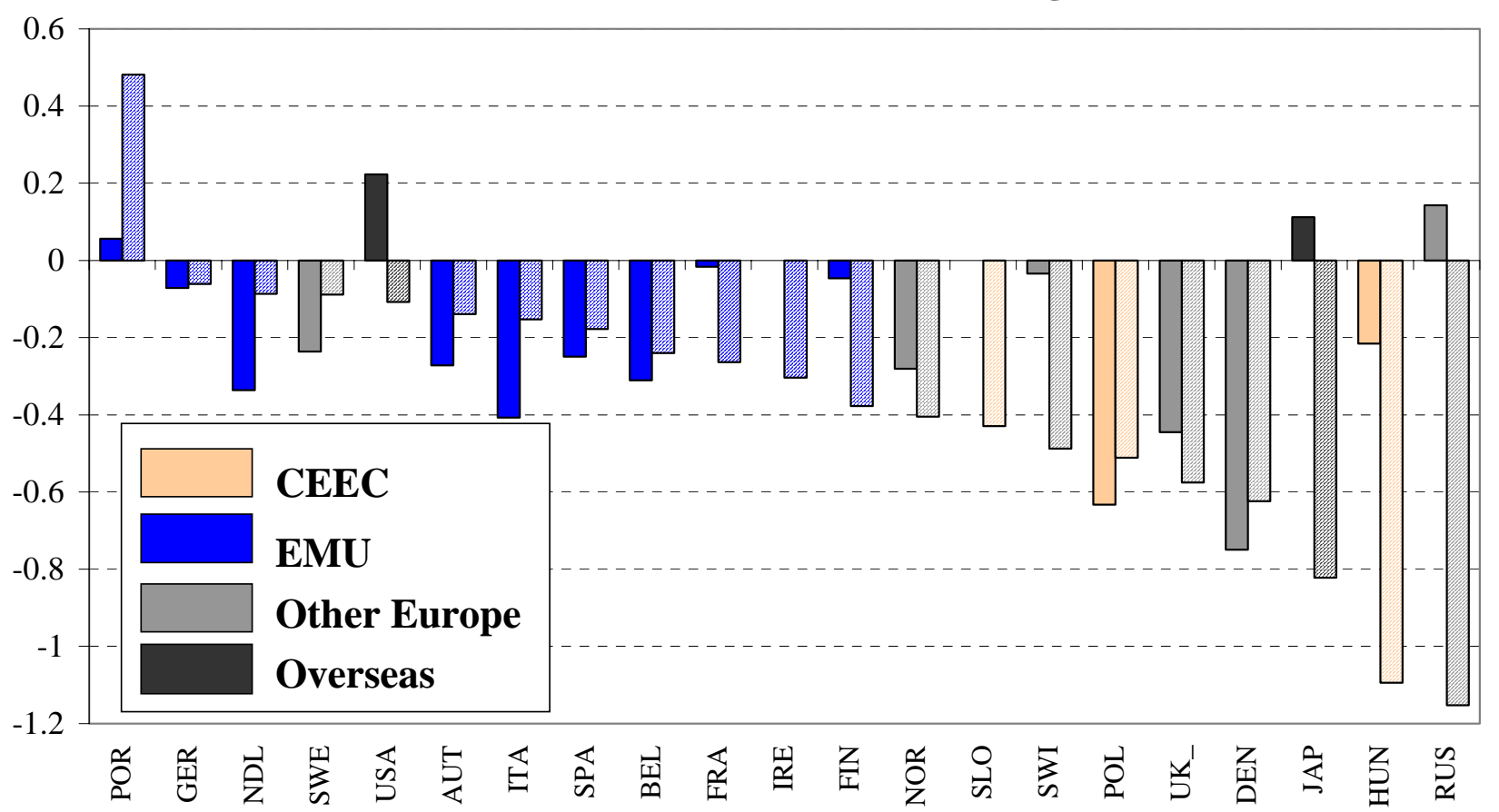

Note: no data are available for Ireland and Slovenia in 1993-97. 